\title{
Chemical Sensors for Farm-to-Table Monitoring of Fruit Quality
}

\author{
Denise Wilson
}

check for

updates

Citation: Wilson, D. Chemical Sensors for Farm-to-Table Monitoring of Fruit Quality. Sensors 2021, 21, 1634. https://doi.org/10.3390/ s21051634

Academic Editor: Alisa Rudnitskaya

Received: 3 February 2021

Accepted: 23 February 2021

Published: 26 February 2021

Publisher's Note: MDPI stays neutral with regard to jurisdictional claims in published maps and institutional affiliations.

Copyright: (C) 2021 by the author. Licensee MDPI, Basel, Switzerland. This article is an open access article distributed under the terms and conditions of the Creative Commons Attribution (CC BY) license (https:/ / creativecommons.org/licenses/by/ $4.0 /)$.
Department of Electrical and Computer Engineering, University of Washington, Seattle, WA 98195-2500, USA; denisew@uw.edu; Tel.: +1-206-221-5238

\begin{abstract}
Farm-to-table operations produce, transport, and deliver produce to consumers in very different ways than conventional, corporate-scale agriculture operations. As a result, the time it takes to get a freshly picked fruit to the consumer is relatively short and the expectations of the consumer for freshness and quality are high. Since many of these operations involve small farms and small businesses, resources to deploy sensors and instruments for monitoring quality are scarce compared to larger operations. Within stringent power, cost, and size constraints, this article analyzes chemical sensor technologies suitable for monitoring fruit quality from the point of harvest to consumption in farm-to-table operations. Approaches to measuring sweetness (sugar content), acidity ( $\mathrm{pH}$ ), and ethylene gas are emphasized. Not surprisingly, many instruments developed for laboratory use or larger-scale operations are not suitable for farm-to-table operations. However, there are many opportunities still available to adapt $\mathrm{pH}$, sugar, and ethylene sensing to the unique needs of localized farm-to-table operations that can help these operations survive and expand well into the future.
\end{abstract}

Keywords: farm-to-table; community-supported agriculture; sustainable agriculture; $\mathrm{pH}$ sensors; Brix sensors; sugar content; ethylene sensors

\section{Introduction}

At its core, farm-to-table is a social movement organized to provide economic benefits to local communities, reduce the climate and environmental impacts of growing food for human consumption, and improve the nutritional value and flavor of food at the point of consumption. Farm-to-table also goes by other similar names including farm-to-fork, farm-to-school, locally-sourced, and farm-to-cafeteria. While not a regulated term, farmto-table is characterized by food that reaches the point of consumption directly from a farm rather than going through a store, distributor, storage, or other stop along the way. Food grown for human consumption can travel through the shortened, local supply chain characteristic of farm-to-table practices through community-supported agriculture (CSA), a farmer's market, or other direct sales relationship that allows individual consumers, restaurants, or other food service businesses to obtain food directly from known, reliable, and local sources.

Farm-to-table significantly reduces the carbon footprint involved in food transport and distribution. Nearly half of all the fruit sold in the U.S. is imported and even produce grown in North America travels an average of 2,000 km from where it is farmed to where it is sold [1]. Despite the long distances that fruit and vegetables travel to reach the consumer, transportation of food accounts for only $11 \%$ of the greenhouse gas emissions incurred by food production [2]. Nevertheless, farm-to-table operations require food to be transported over much smaller distances than food produced by corporate agriculture or imported from other countries. Shorter distances require less diesel and other fossil fuel consumption and reduce the carbon footprint of the fruit production life cycle. As a percentage of overall greenhouse gas emissions, these reductions are even larger for fruit and vegetables per $\mathrm{kg}$ than for meat production because fruits require far less land use change and do not incur the significant methane emissions involved in raising cattle and other farm animals [3]. 
As or more important than greenhouse gas emissions incurred when fruit must travel long distances to reach the point of consumption are the nutrients lost between harvest and consumption. Fruits and vegetables typically contain over $90 \%$ water and once they are harvested, respiration rates increase, moisture decreases, and fruit quality degrades rapidly [4]. While refrigeration can slow down respiration processes and allow for longer shelf lives, nutrients inevitably degrade with time after harvest [4]. Of all nutrients lost with storage or transport of fresh fruit and vegetables, post-harvest decreases in vitamin C are the most dramatic, but riboflavin, folic acid, pantothenic acid, and biotin are also highly sensitive to post-harvest conditions and decline with increased temperatures and storage times [5]. However, in lemons and grapefruit, very little vitamin $C$ is lost during storage and in reasonable storage conditions, losses of vitamin $C$ for other citrus fruits are quite small. Unlike vitamin C, precursors to vitamin A (e.g., carotene) are stable and suffer little during storage [5]. In contrast, polyphenolics (e.g., flavonoids) decrease significantly with the storage of fresh produce [6]. Thus, while conventional wisdom may promote the idea that a freshly picked fruit is always more nutritious than one stored, evidence suggests that nutrient degradation after harvest is much more of a mixed bag. Nevertheless, combined with small farm practices, both fruits and vegetables supplied by farm-to-table operations are likely to offer greater nutritional value and flavor than produce generated by corporate agriculture operations.

Farm-to-table operations also benefit local economies and small farms. Between 1948 and 2015 in the United States, four million farms disappeared even as farm output doubled [7]. While this statistic alone underscores the crisis that small farms face in modern agriculture, the rise in demand for fresher and better tasting food among consumers has both helped and hindered the fight that small farms face to survive. In order to be successful in farm-to-table, small farms must diversify the fruits, vegetables, and other products that they produce, devise strategies to supply products such as cold storage vegetables and meat during the winter months, and invest in multiple supply chains ranging from direct-to-consumer farmers markets to restaurant supported agriculture [8]. Ensuring that consistently high quality of produce are delivered to a myriad of customers will continue to enable the farm-to-table movement to expand.

As with corporate agriculture, the judicious use of sensor technologies in the monitoring, harvest, sorting, and transport of farm-to-table products can support greater yields, reduce waste, and improve profit margins. However, what needs to be sensed and when can be drastically different than the longer, more complex and more controlled food supply chains inherent to corporate agriculture. This article takes a closer look at the farm-to-table supply chain and opportunities for sensors to support the continued optimization and expansion of this important social movement.

In the context of farm-to-table operations, the chemical composition of fruits and vegetables is clearly a major contributor to the exceptional taste, flavor, and overall quality expected of localized food production operations. However, the chemical composition of fruits is complex and varies widely among different fruit types and cultivars. For fruits, how sweet, how acidic, and how ripe a fruit is as well as how these qualities change over time are very important to maximizing the value of what is delivered to the consumer, whether at the restaurant or at home. Therefore, this review of chemical sensor technologies focuses on these three parameters (sweetness/sugar content, acidity/pH, and ripeness/ethylene emissions) not because they are all that matters in determining fruit quality but because they are common to all fruits in influencing overall quality.

\section{Chemistry of Interest in Farm-to-Table Operations}

In farm-to-table operations, the quality of individual fruit is far more important than it is in higher volume and canning/preserving operations. The chemical composition of the fruit is only part of what is used to determine both perceived and actual quality. Other parameters such as color, shape, texture, and homogeneity also influence the perception of quality. Almost everyone loves a lush red, symmetric tomato, but some attributes such as 
color also indicate nutritional quality. For instance, the red color in the traditional tomato is highly correlated to the amount of lycopene it contains and the many nutritional benefits that lycopene offers to human health [9]. Furthermore, color has long been used as an indicator of how mature a fruit is and plays a role in determining the optimal point of harvest [10]. In combination, color and firmness are also used together to not only track maturation of the fruit prior to harvest but to predict and monitor post-harvest degradation [11]. Ironically, many of these visible indicators are often used by the consumer as the sole indicators of quality while the underlying chemical composition which determines these indicators and their change over time is what matters much more in terms of flavor and nutritional value. Chemical sensors offer the opportunity to make the invisible chemistry of plants, produce, and food visible and data collected from these sensors can complement visual indicators of fruit quality.

\subsection{Sugar Content}

Sugar plays an important role in what makes a fruit taste good and is a critical parameter for monitoring and determining the quality of fruit as it travels from farm to table. Many fruits are mostly water but what remains after water is taken out of the equation is dominated by different types of sugar whose concentrations evolve during the ripening process. For example, while a tomato is between $90 \%$ and $95 \%$ water, $50 \%$ of what remains is sugar and is represented by glucose, fructose, and sucrose. Sugar is a major component of tomato flavor both in terms of the total amount of sugar in the tomato and in the amount relative to the acid also present in the tomato. During ripening, sugar content increases during the ripening process and by the time a tomato is mature, glucose and fructose contribute approximately equal amounts to the total sugar content while sucrose is a more minor contributor [12]. Furthermore, degradation of tomato acids during maturation and ripening leads to the accumulation of sugars in the fruit. Thus, not only are sugar and acid content largely responsible for fruit sweetness and sourness but the balance between them is an indication of ripening stage. While total sugar content does not tell the full story regarding the quality and taste of fruit, it is nevertheless an important parameter to measure both in fruit and fruit juice and many instruments for measuring it are commercially available. Total sugar content is often expressed in units of degrees Brix. One degree Brix is equal to one gram of sucrose in $100 \mathrm{~g}$ of solution or 1\% sucrose by mass. Multiplying degrees Brix by 10 gives the amount of sucrose in solution by volume. One degree Brix is therefore equal to $10 \mathrm{~g}$ of sucrose per liter of solution. In the case of fruit, solution refers to either a fruit juice or a mash made by processing the intact fruit until it approximates a solution. Degrees Brix ( ${ }^{\circ}$ Brix) have been extensively characterized according to quality of fruit and the change in ${ }^{\circ}$ Brix over time can be used as a valuable indicator of the maturation and over-ripening of fruit during transport and storage. Estimates of fruit quality according to sugar content often use the broadly accepted Brix chart formulated by agricultural engineer Dr. Carey Reams. A representative sampling of fruits from the Brix chart is provided in Table 1 [13].

While Brix values are important, they do not tell the whole story when it comes to the flavor and quality of fruit. Brix measurements assume that the dissolved solids that are being measured consist entirely of sucrose. While in most fruits, sugars are the majority of soluble solids, other soluble solids include carbohydrates, organic and amino acids, proteins, fats, and minerals. The presence of these other soluble solids can lead to overestimates of the amount of sugar in fruits and fruit juices. For example, in some mangoes, total soluble solids content (TSS) at the point of harvest are approximately $8.7 \%$ while the sugar content is only $6.1 \%$ [14]. Similarly, the TSS of certain pears can be as high as $23.0 \%$ while the total sugar content is only $10.4 \%$ [15]. Furthermore, fruits contain sugars other than sucrose which lead to additional errors in Brix measurements. For instance, tomatoes contain $1.1 \mathrm{~g}$ of glucose, $1.14 \mathrm{~g}$ of fructose, and $0 \mathrm{~g}$ of sucrose, while peaches contain $1.1 \mathrm{~g}$ of glucose, $1.3 \mathrm{~g}$ of fructose and $5.6 \mathrm{~g}$ of sucrose per $100 \mathrm{~g}$ of ripe fruit [16]. Further, in the big picture of fruit flavor and perceived quality, an understanding of both acidity and 
sugar content is necessary to more fully understand the taste of fruit and its role in overall perceived quality. In farm-to-table operations where the value of flavor is at a premium, measuring both acidity and sugar content is critical to accurately gauging flavor.

Table 1. Sugar Content in Fruit across a Range of Fruit Quality [13].

\begin{tabular}{lcccc}
\hline \multirow{2}{*}{ Fruit } & \multicolumn{4}{c}{${ }^{\circ}$ Brix Associated with Quality of Fruit } \\
\cline { 2 - 5 } & Poor & Average & Good & Excellent \\
\hline Apple & 6 & 10 & 14 & 18 \\
Banana & 8 & 10 & 12 & 14 \\
Cantaloupe & 8 & 12 & 14 & 16 \\
Cherries & 6 & 8 & 14 & 16 \\
Grapes & 8 & 12 & 14 & 20 \\
Grapefruit & 6 & 10 & 14 & 18 \\
Lemons & 4 & 6 & 8 & 12 \\
Mangoes & 4 & 6 & 10 & 14 \\
Oranges & 6 & 10 & 16 & 20 \\
Peaches & 6 & 10 & 14 & 18 \\
Pears & 6 & 10 & 12 & 14 \\
Strawberry & 6 & 6 & 8 & 16 \\
Tomato & 4 & 6 & 8 & 12 \\
Watermelon & 4 & &
\end{tabular}

\section{2. $P H$ and Acidity}

Acidity in fruit can be measured either by sensing $\mathrm{pH}$ in the juice of the fruit or by measuring titratable acidity. Titratable acidity measurements typically require adding a known basic solution to the fruit juice until the solution transitions from an acid to neutral. The amount of base added to neutralize the solution is then a measure of how much acid was present in the original juice. The titration process takes time and is best suited to lab or benchtop situations rather than in-field or other in situ measurements. In contrast, $\mathrm{pH}$ is much easier to measure and a wide range of sensing technologies and instrument designs are available to measure $\mathrm{pH}$ in the field. $\mathrm{pH}$ stands for power of hydrogen and represents the concentration of hydrogen ions in solution. $\mathrm{pH}$ is measured on a scale between 1 and 14, with lower numbers below 6 representing acids and numbers above 9 representing strong bases. Fruits are primarily acidic (Table 2), but some such as cantaloupe and honeydew melon are considered low-acid food, with $\mathrm{pH}$ values over 6 but below neutral $\mathrm{pH}$ (i.e., $7 \mathrm{pH}$ units).

In and of itself, $\mathrm{pH}$ is important as an indicator of food safety in canned and preserved fruits. For example, among the over 12 million tons of tomatoes grown every year in the United States for use in processed products [17], $\mathrm{pH}$ plays a critical role in yield and quality. Among these tomatoes, the $\mathrm{pH}$ must remain low enough to ensure food safety but also high enough to maintain flavor. Despite the fact that tomatoes are not a low-acid food, they must nevertheless be maintained at a pH between 4.2 and 4.3 in canned tomatoes, tomato paste, catsup, and similar products [18]. A maximum safe level of 4.4 with an optimal target $\mathrm{pH}$ of $4.2-4.3$ has been suggested to prevent Clostridium botulinum (botulism) spores from growing and producing toxin [19].

Table 2. pH of Ripe Fruit [20].

\begin{tabular}{lccc}
\hline Fruit & pH Range & Fruit & pH Range \\
\hline Apples & $3.10-3.40$ & Mangoes & $3.40-4.80$ \\
Banana & $4.50-5.20$ & Oranges & $3.69-4.34$ \\
Cantaloupe & $6.13-6.58$ & Peaches & $3.30-4.05$ \\
Cherries & $3.25-3.83$ & Pears & $3.50-4.60$ \\
Grapes & $2.80-3.84$ & Strawberry & $3.00-3.90$ \\
Grapefruit & $3.00-3.75$ & Tomato & $4.30-4.90$ \\
Lemons & $2.00-2.60$ & Watermelon & $5.18-5.60$ \\
\hline
\end{tabular}


However, of much greater relevance to fruit in farm-to-table operations is a combination of $\mathrm{pH}$, sugar content, and flavor volatiles, which together become the taste and flavor of the fruit [21] and also play an important role in dictating the maturation, ripening, and over-ripening of fruit pre- and post-harvest. Both the types of acid in and the nature of $\mathrm{pH}$ changes in fruit can vary widely from one type and cultivar to the next. For example, citrates in peppers and tomatoes both increase during maturation and ripening, but in tomatoes, malates increase until just before full maturity, before decreasing until the tomato reaches optimal ripening conditions. In peppers, however, the trend is opposite. Malates decrease and then increase again to full ripening. Simultaneously, sucrose sugar content decreases during ripening for both tomatoes and peppers while fructose and glucose sugars increase [22]. Furthermore, the dominant organic acid in a fruit varies according to species with malic acid a major player in such fruit as apples [23] and citric acids important among citrus fruits [24]. Even among different cultivars of the same fruit (e.g., pears [25], bananas [26], peach [27]), both total acidity and the mixture of organic acids that contribute to acidity are distinct.

Thus, while sensing $\mathrm{pH}$ is directly useful for predicting the food safety of canned or preserved products, it is not particularly useful as a sole measurement for fresh fruit. When used in combination with the measurement of sugar content, however, sensing $\mathrm{pH}$ can provide a much more relevant (although still not complete) picture of fruit quality. Accessible, low-cost $\mathrm{pH}$ sensing technology can therefore play a valuable role in farm-to-table operations.

\subsection{Ethylene Emission and Absorption}

In terms of ripening, there are two major types of fruit. Those that continue to ripen after harvest (e.g., apples, tomatoes) are called climacteric while those that do not ripen after harvest (e.g., strawberries, grapes) are termed non-climacteric. The ripening process in climacteric fruit is controlled by the production of ethylene gas, a phytohormone (i.e., plant hormone) that acts as a chemical messenger to regulate the cellular activities involved in ripening. In the climacteric fruit, ethylene production increases during maturation, rising sharply right before optimal ripening and then decreasing dramatically as the fruit ages, over-ripens, and degrades. In contrast, while non-climacteric fruits also produce some ethylene gas, they do not experience the sharp increases in ethylene production that characterize the ripening of climacteric fruit nor the dramatic decreases that occur during over-ripening (Figure 1).

And, as is the case with $\mathrm{pH}$ and sugar content, the amount of ethylene produced and the sensitivity of fruits to ethylene can vary widely with species and cultivar (Table 3). Recent research has shown that the distinction between climacteric and non-climacteric fruit is blurred, as many climacteric fruits (e.g., pears) now exhibit some non-climacteric behaviors or include non-climacteric cultivars and the opposite is true for some nonclimacteric fruits (e.g., strawberries) [28].

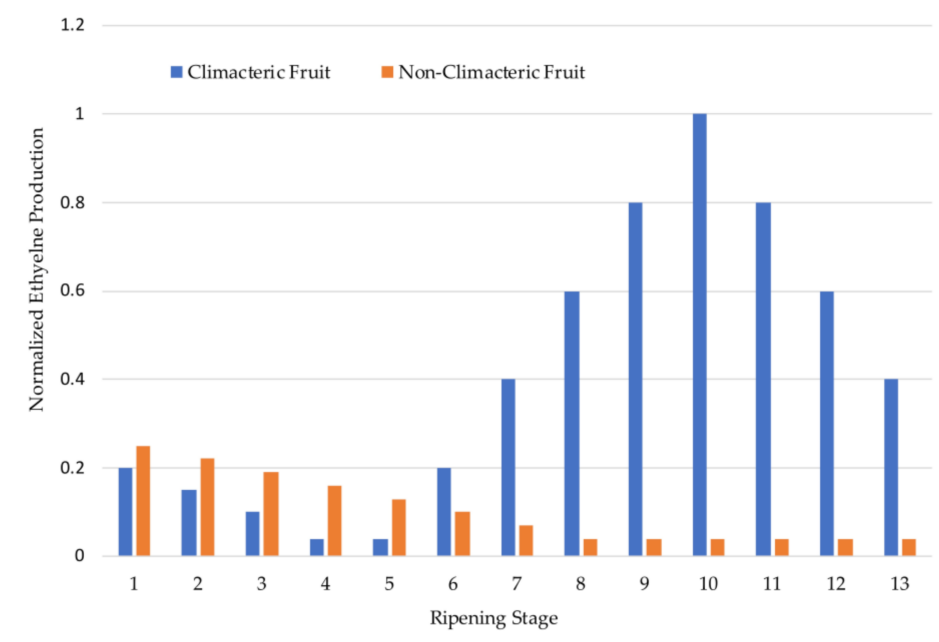

Figure 1. Ethylene Production in Climacteric and Non-Climacteric Fruits. Adapted from [29]. 
Table 3. Ethylene Production and Sensitivity in Fruit. NA: not available.

\begin{tabular}{lcccc}
\hline \multirow{2}{*}{ Fruit } & Type [28] & \multicolumn{2}{c}{ Production [30,31] } & Ethylene Sensitivity \\
\cline { 3 - 3 } & & Relative & $\mu \mathrm{L} / \mathbf{k g}-\mathbf{h}$ & \\
\hline Apples & climacteric & high & $10-100$ & high \\
Banana & climacteric & moderate & $1-10$ & high \\
Cantaloupe & climacteric & NA & NA & very low \\
Cherries & non-climacteric & very low & $<0.1$ & low \\
Grapes & non-climacteric & very low & $<0.1$ & low \\
Grapefruit & non-climacteric & very low & $<0.1$ & moderate \\
Lemons & non-climacteric & very low & $<0.1$ & moderate \\
Mangoes & climacteric & moderate & $1-10$ & high \\
Oranges & non-climacteric & very low & $<0.1$ & moderate \\
Peaches & climacteric & high & $10-100$ & high \\
Pears & climacteric & high & $10-100$ & high \\
Strawberry & non-climacteric & very low & $<0.1$ & low \\
Tomato, ripe & climacteric & moderate & $1-10$ & low \\
Watermelon & non-climacteric & low & $0.1-1.0$ & high \\
\hline
\end{tabular}

In conventional agriculture, ethylene emissions by fruits are often inhibited by the introduction of 1-methylcyclopropene (1-MCP) to delay ripening or are externally controlled with additional ethylene gas to speed up ripening after transport and prior to sale [32]. While these steps are largely unneeded in farm-to-table operations, natural ethylene emissions from fruits and vegetables can still cause deterioration and over-ripening, particularly when moderate to high ethylene emitters are packaged or stored with ethylene-sensitive produce. For example, broccoli and apples are both in season in the fall months, while the former is ethylene sensitive and the latter is an ethylene producer [33]. Packaging both in the same farm box for delivery to residential households or storing both in the same place at a restaurant can lead to premature yellowing of broccoli, loss of nutrients, and reductions in flavor. Thus, it is important to know both the ambient ethylene gas concentration among fruits during transport and storage as well as the type of fruits that are in close proximity to one another. Tracking the rate of change of ethylene production among climacteric fruits at the point of harvest is also very useful in predicting ethylene exposure during post-harvest operations. If transport and storage times and conditions (e.g., temperature and humidity) are known, these gradients in ethylene production can be used to harvest fruit at such a time that optimal freshness is reached at the point of consumption. In farm-to-table operations, customer expectations for fruit freshness are often higher than for fruits which traverse a longer supply chain and which often undergo artificial manipulation of the ripening process en route. Because of these increased expectations, monitoring ambient ethylene gas concentration among farm-to-table fruit can be as or more important in establishing, tracking, and predicting fruit quality as it is for corporate fruit production.

Ethylene sensors can be useful for reducing the detrimental impacts of ethylene gas in farm-to-table operations in three general ways: (a) monitoring ethylene gas pre-harvest to determine optimal ripening; (b) characterizing amount and temporal variations in ethylene emissions from mixtures of various fruits and vegetables in experimental research settings to provide guidance to small farms on what and how much can be packaged together; or (c) deploying portable ethylene sensors to monitor fruits and vegetables whether or not they are transported or stored together. The former approach allows for established benchtop or laboratory methods of ethylene sensing to be viable while the latter approach requires low-cost, low-power, portable, and small sensors.

\section{Sensing Technologies for Sweetness (Sugar Content)}

Sugar content in fruit is typically measured in degrees Brix, where one degree represents one gram of sucrose (sugar) in $100 \mathrm{~g}$ of solution. Most sensors used to measure sugar content assume that most or all of the sugars present in a sample are sucrose. When this is 
not the case, small errors introduced by other sugars (e.g., fructose, glucose) are usually expected and tolerated. Many methods also sense sugar content indirectly by measuring the total dissolved solids in a liquid sample. These indirect methods are vulnerable to interference from other dissolved solids (e.g., proteins, fats, minerals), but also enable simple, low-power, and inexpensive instruments. Therefore, they remain popular in estimating the sugar content not only of fruit and fruit juice but also of wine, honey, carbonated beverages, maple syrup, and similar products. Indirect methods of determining degrees Brix (i.e., sucrose content) include measuring the specific gravity of a solution using a hydrometer or oscillating U-shaped tube meter, or alternatively, measuring refractive index (RI) using a refractometer. Optical sensor modalities such as surface plasmon resonance compete with traditional refractometer instruments to offer very high resolutions in determining RI. However, these indirect methods share the common problem of requiring that juice be extracted from the fruit or that the fruit be processed into a mash that is sufficiently liquid and homogenous for a reliable measurement. This process is generally destructive to the fruit itself and particularly so for firm fruits which are difficult to mash. Microextraction methods and miniaturized measurement instruments have the potential to draw sufficiently small sample volumes to enable non-destructive evaluation of fruit sweetness using these measurement methods. At the present time, however, such non-destructive approaches to sampling fruit and measuring degrees Brix are not commercially available. However, sugar sensing methods that capitalize on the absorption of infrared (IR) light and the speed of sound inside a fruit can be performed non-destructively. IR methods offer the added benefit of a more direct measure of sucrose content that is more resistant to interference from related compounds or other dissolved solids as compared to indirect sensing methods that use specific gravity or RI to infer ${ }^{\circ}$ Brix.

\subsection{Hydrometers and U-Shaped Tube Meters}

Both hydrometers and oscillating U-shaped tube meters estimate sugar content by measuring specific gravity. When applied to liquids, specific gravity is the ratio of the density of a liquid relative to that of water when it is in its most dense state (at $4{ }^{\circ} \mathrm{C}$ ). The specific gravity of typical fruit juices varies between 1.02 and 1.05 [34] and is linearly related to degrees Brix within this range [35]:

$$
{ }^{\circ} \text { Brix } \sim 248 * \text { Specific Gravity }-248
$$

The hydrometer (Figure 2a) uses buoyancy to estimate specific gravity by inserting the instrument into a liquid of unknown specific gravity until it floats. The greater the density and specific gravity of a fruit juice, the denser the solution is and the higher the hydrometer bulb will float. Hydrometers are typically customized to the range of specific gravities expected in the measurement process and can cost anywhere from $\$ 10$ for home winemaking and beer brewing [36] to hundreds of dollars for instruments that measure specific gravity in 0.001 increments [37].

An oscillating U-shaped tube (Figure $2 b$ ) can also be used to measure specific gravity. A liquid sample (e.g fruit juice or fruit mash) fills a U-shaped tube and the tube is electrically excited with a piezoelectric actuator which stimulates the liquid to oscillate in the tube. The period of oscillation is related to the density and specific gravity of the liquid and is sensed by using two optical sensors on either side of the U-shaped tube. Density and specific gravity of liquids can be measured with precision and resolution as high as $10^{-6}$ using the oscillating U-shaped tube but these instruments often cost thousands of dollars and are prohibitively expensive and too large [38] for farm-to-table applications.

Using hydrometers or oscillating U-shaped tube meters to measure sugar content presumes that the only contributor to specific gravity changes is sucrose. Thus, regardless of the resolution and precision of the specific gravity measurement itself, this approach to measuring sugar content is vulnerable to inaccuracies introduced by the presence of other molecules or solids that influence specific gravity as well as by the type and composition of sugar present in a sample. 


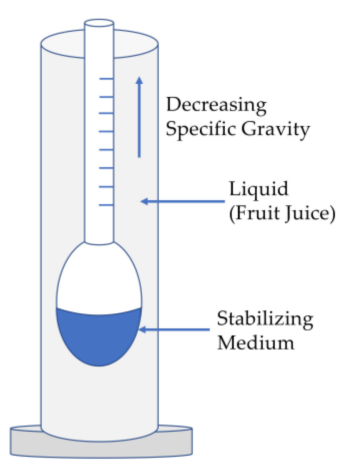

(a)

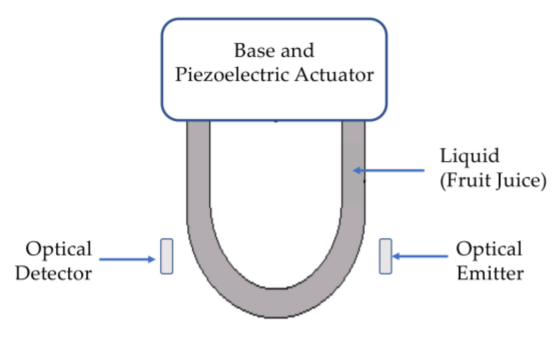

(b)

Figure 2. Instruments for Measuring Specific Gravity of Fruit Juice or Fruit Mash. (a) Typical hydrometer; and (b) oscillating U-shaped tube meter.

\subsection{Refractive Index Sensors}

As sugar (e.g., sucrose) concentration in a liquid solution (e.g., fruit juice) increases, light entering into the solution travels more slowly and bends (refracts) more. This behavior is expressed as an increase in the refractive index (RI) of the solution. Except for some small curvature at high concentrations, the RI of sucrose in solution increases linearly with increasing sucrose concentration at a given wavelength and temperature. For example, at a range of ${ }^{\circ}$ Brix relevant to fruit (corresponding to 0 to $15 \%$ dissolved sugar) and for a wavelength of $589 \mathrm{~nm}$ at a temperature of $20^{\circ} \mathrm{C}$, degrees Brix can be estimated according to the following expression [39]:

$$
{ }^{\circ} \text { Brix } \sim 667 * R I-889
$$

Temperature has a significant influence on RI-on the order of a $10^{-4}$ decrease in RI units per one ${ }^{\circ} \mathrm{C}$ increase in temperature for water-based solutions [40].

A traditional RI sensor, called a refractometer, directs light through a liquid sample to a prism that is in contact with a sample (e.g., fruit juice) along a wide range of incident angles (Figure 3). When the incoming light reaches the interface between the prism and the sample at an angle that is less than the critical angle, some light is refracted and some light is reflected onto the light sensor array. At angles greater than the critical angle, all light is reflected onto the array. If the human eye is used instead of an electronic array of light sensors, the refractometer can be operated at zero power, as is the case with a handheld or analog refractometer. Abbe refractometers use two prisms, on-board temperature sensors, and circulating water to control temperature for high-precision measurements of refractive index.

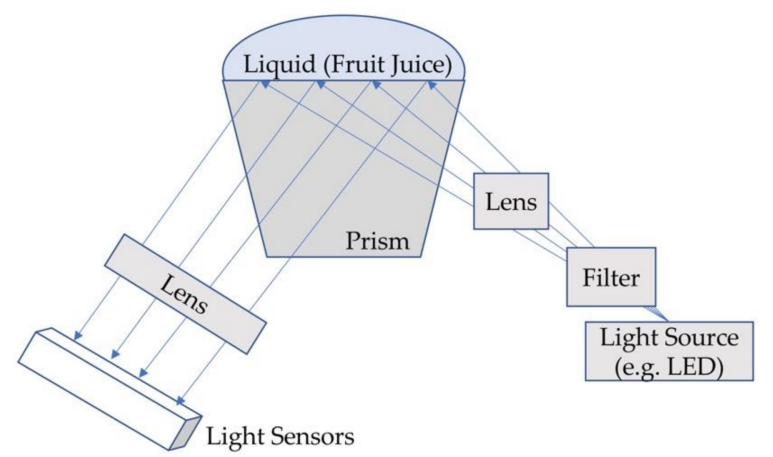

Figure 3. Traditional Refractometer Configuration.

Analog refractometers are quite inexpensive, offer precision on the order of $10^{-4} \mathrm{RI}$ units $\left(0.1^{\circ}\right.$ Brix $)$, and are available commercially for less than $\$ 300$; their portability, zero 
power consumption, and low cost make them well suited to monitoring fruit at the point of harvest. Digital refractometers cost more (on the order of \$500), consume power, are less vulnerable to human error, and offer similar precision $\left(0.1^{\circ}\right.$ Brix $)$ as analog units. Abbe refractometers offer as good or better resolution to digital and analog refractometers and greater accuracy in response to ambient temperature fluctuations but are designed for laboratory use and are prohibitively expensive for most farm-to-table applications.

A number of alternative optical sensor technologies for measuring RI (and by extension sugar content in fruit juice) have been demonstrated in the literature. For example, saurface plasmon resonance (SPR) is a physical process by which energy from incoming light is coupled to energy associated with free electrons in a noble metal such as gold. At a fixed wavelength, only light incident upon the metal at a particular angle is optimally absorbed by the free electrons and converted to surface plasmons. Surface plasmons are delocalized oscillations of electrons that occur at the interface of two materials whose dielectric functions have real components which are opposite sign (i.e., one positive and one negative) such as is the case between a noble metal and air. The angle at which optimal or maximum absorption of the light energy occurs is called the point of surface plasmon resonance and is dependent on the $\mathrm{RI}$ of the material in contact with the noble metal. Alternatively, if the angle of incident light is held constant, SPR can be measured by finding the wavelength of light at which the maximum amount of light energy is absorbed by surface plasmons. In either case, SPR is highly sensitive to refractive index, delivering resolutions as high as $1 \times 10^{-7}$ to $2 \times 10^{-7} \mathrm{RI}$ units at wavelengths between 700 and $900 \mathrm{~nm}$ [41]. Similar resolutions are possible with fused silica microsphere resonators where light travels in the form of whispering gallery modes (WGM) along the curved surface of the spheres. Similar to fixed angle SPR, the wavelength of these resonant WGM resonators is very sensitive to the RI of the surrounding medium, providing RI resolution as low as $1 \times 10^{-7} \mathrm{RI}$ units [42]. Recent advances in microsphere design have enabled the discrimination of temperature changes from RI changes in the liquid sample, thus providing much needed improvements in accuracy when these RI sensors are used in field environments where ambient temperatures can vary widely [43]. Other optical structures are also sensitive to RI changes but deliver lower RI resolution. Those based on photonic crystal microcavities can detect RI at $10^{-3}$ RI units of resolution in liquids [44] and $10^{-4} \mathrm{RI}$ unit resolutions in gases [45]. Photonic crystal fibers containing long period gratings have been demonstrated with RI resolutions of $8.5 \times 10^{-6}$ RI units [46].

\subsection{Alternative Approaches}

Another indirect approach to measuring sugar content in solution involves the use of capacitive sensors. Capacitance depends on the permittivity of the dielectric between the two measurement plates (i.e., electrodes) of a capacitor. Permittivity changes with sugar content in solution, and the permittivity of both water and sucrose varies with frequency with larger differences between sugar and water evident at lower frequencies (below $1 \mathrm{MHz}$ ). These differences can be exploited to generate characteristic frequency vs. voltage curves for sucrose solutions that provide estimates of the amount of sucrose in solution. This method has been successfully demonstrated for detecting sucrose in solution at concentrations between 10\% (100 g/L) and 50\% (500 g/L) [47] and between $9.0^{\circ}$ Brix and $10.9^{\circ}$ Brix in orange fruit [48]. As an indirect measure of sugar concentration, capacitive-based sugar sensors are as vulnerable as all other indirect sensing methods to interference from other solids and different compositions of sugar in solution.

Ultrasound provides yet another alternative to measuring sugar content, density, and refractive index in fruit and fruit juices. Sound travels more slowly in materials that are denser. Increasing sugar content is linked to increasing fruit density and slower speed of sound through the fruit. This property has been used to measure sugar content in fruit juice across a range of $0-40{ }^{\circ}$ Brix within an error of $0.2 \%$ for juices that are dominated by a single sugar and $0.5 \%$ for juices that contain multiple types of sugar [49]. Ultrasonic measurements have also been used to identify sugar content in intact fruits or fruit samples 
including mangos, tomatoes, melons, and plums [50]. As with many other methods to measuring sugar, ultrasound is prone to interference from other dissolved solids and also demonstrates limited accuracy compared to RI-based sensors.

\subsection{Summary of non-Spectroscopic Technologies}

Multiple sensor technologies are available to measure sugar content in fruits and fruit juices including those based on specific gravity (hydrometers, oscillating U-shaped tube meters), RI (analog, digital, Abbe, SPR, microsphere), capacitance, and the speed of sound. Several of these methods provide very high accuracy and resolution across a range of ${ }^{\circ}$ Brix relevant to fruits and fruit juices (Table 4). However, common to all of these approaches is an underlying assumption that changes in the output parameter (e.g., specific gravity, RI) are dominated by variations in sucrose content in the fruit or fruit juice. The presence of other sugars, particularly fructose and glucose, introduce interference and error to these sensing approaches. Further, while these sensors and instruments can be used non-destructively in the evaluation of fruit juice, the same is not the case for intact fruit. In order to estimate sugar content, the fruit must be converted to a mash which inherently destroys the fruit in the process. While this may work for sampling of sweetness in batches of fruit, monitoring of the sweetness or sugar content of individual fruit requires a nondestructive sensing or sampling technique. Of the major sensing technologies available to evaluate sugar content non-destructively, light spectroscopy is one of the only viable options. Because of the absorption characteristics of sugar, light in the near-infrared region of the electromagnetic spectrum provides the best choice of wavelengths for analyzing sugar content in fruit. Near-infrared (NIR) spectroscopy methods are discussed next.

Table 4. Sensors for Measuring Sugar Content in Fruit and Fruit Juice (NS: not specified).

\begin{tabular}{|c|c|c|c|c|c|}
\hline Instrument/Sensor & Ref & Accuracy & Range & Resolution & Cost \\
\hline \multicolumn{6}{|c|}{ Using specific gravity: SG Units ( ${ }^{\circ}$ Brix) } \\
\hline Hydrometer $^{1}$ & {$[51]$} & NS & $0.98-1.16\left(0-40^{\circ}\right)$ & NS & $\$ 12$ \\
\hline Hydrometer 1 & [52] & $\operatorname{NS}\left(0.50^{\circ}\right)$ & NS $\left(0-35^{\circ}\right)$ & $\left(0.5^{\circ}\right)$ & $\$ 100$ \\
\hline Hydrometer ${ }^{1}$ & {$[37]$} & NS & $>1\left(>0^{\circ}\right)$ & $1 \times 10^{-3}\left(0.25^{\circ}\right)$ & $\$ 46$ \\
\hline U-Shaped Tube Meters ${ }^{2}$ & {$[53]$} & $1 \times 10^{-3}\left(0.25^{\circ}\right)$ & $0.0-3.0\left(0-100^{\circ}\right)$ & $1 \times 10^{-4}\left(0.025^{\circ}\right)$ & $\$ 3290$ \\
\hline \multicolumn{6}{|c|}{ Using refractive index: RI Units $\left({ }^{\circ}\right.$ Brix $)$} \\
\hline Refractometer (analog) ${ }^{1}$ & {$[54]$} & NS & NS & $1 \times 10^{-4}\left(0.1^{\circ}\right)$ & $\$ 133$ \\
\hline Refractometer (digital) ${ }^{1}$ & {$[55]$} & $3 \times 10^{-4}\left(0.20^{\circ}\right)$ & NS & $1 \times 10^{-4}\left(0.1^{\circ}\right)$ & $\$ 500$ \\
\hline Refractometer (Abbe) ${ }^{2}$ & [56] & $2 \times 10^{-4}\left(0.14^{\circ}\right)$ & $1.3-1.7\left(0-100^{\circ}\right)$ & $2 \times 10^{-4}\left(0.14^{\circ}\right)$ & $\$ 6630$ \\
\hline Photonic Crystal Microcavities & [45] & NS & $1.0003-1.0013^{4}$ & $1 \times 10^{-4}\left(0.07^{\circ}\right)$ & $\mathrm{NA}^{3}$ \\
\hline $\begin{array}{l}\text { Photonic Crystal Fibers } \\
\text { w/long period gratings }\end{array}$ & {$[46]$} & NS & $1.33-1.38\left(0-33^{\circ}\right)$ & $8.5 \times 10^{-6}\left(0.006^{\circ}\right)$ & $\mathrm{NA}^{3}$ \\
\hline Surface Plasmon Resonance & {$[41]$} & NS & NS & $1 \times 10^{-7}\left(0.000071^{\circ}\right)$ & $\mathrm{NA}^{3}$ \\
\hline Resonating Microspheres & [42] & NS & NS & $1 \times 10^{-7}\left(0.000071^{\circ}\right)$ & $\mathrm{NA}^{3}$ \\
\hline \multicolumn{6}{|c|}{ Using capacitance: Farads ( ${ }^{\circ}$ Brix $)$} \\
\hline Parallel Plate Capacitors & {$[47]$} & NS & NS & NS $\left(5.0^{\circ}\right)$ & $\mathrm{NA}^{3}$ \\
\hline Cylindrical Capacitors & [48] & NS & NS & $4.22-5.02 \mathrm{pF}\left(9.0^{\circ}-10.9^{\circ}\right)$ & $\mathrm{NA}^{3}$ \\
\hline \multicolumn{6}{|c|}{ Using the speed of sound: $\mathrm{m} / \mathrm{sec}\left({ }^{\circ} \mathrm{Brix}\right)$} \\
\hline Ultrasound (one sugar) & [49] & NS $\left(0.2^{\circ}\right)$ & $\left(0^{\circ}-40^{\circ}\right)$ & NS & $\mathrm{NA}^{3}$ \\
\hline Ultrasound (intact fruit) & {$[50]$} & NS & $\left(1.5^{\circ}-17.5^{\circ}\right)$ & NS & $\mathrm{NA}^{3}$ \\
\hline
\end{tabular}

${ }^{1}$ Available commercially as a portable instrument. ${ }^{2}$ Available commercially as benchtop (laboratory) equipment. ${ }^{3}$ Research; no commercial version available. ${ }^{4}$ Measured for gases only; RI range is not matched to liquid sensing applications.

\subsection{Near-Infrared (NIR) Spectroscopy}

Limited by laws of quantum mechanics, the absorption of near-infrared light by solid materials is limited to overtone and combination vibrations in a molecule. Because these vibrations are limited, molar absorptivity in the NIR region of the electromagnetic spectrum is small and provides only low sensitivity measurements. However, the absorption of 
common sugars (sucrose, fructose, glucose) is distinct in the NIR region and exhibits subtle variations around a wavelength of $960 \mathrm{~nm}$ that make it possible to distinguish among them [57]. Further, the fact that NIR penetrates solid materials to larger depths than other forms of IR spectroscopy makes it possible to analyze solid materials such as fruit without a lot of sample preparation. Further, among the shorter wavelengths of the NIR spectrum, conventional silicon photodetectors may be used to detect transmitted or reflected NIR light, thus opening the door for affordable and portable NIR instruments that can take advantage of the low cost of silicon relative to other semiconductor photodetectors. Several handheld NIR spectrometers are presently available commercially although their performance and usefulness has yielded mixed reviews [58] and these instruments can easily cost into the thousands of dollars.

The advantages of NIR approaches to detecting sugar content have led to numerous studies of fruit using NIR spectroscopy. The response of fruits to NIR can be evaluated in multiple ways. NIR absorption spectroscopy studies how much light is absorbed while transmittance (Figure 4a) evaluates how much NIR is transmitted through a liquid or solid. Reflectance (Figure $4 \mathrm{~b}$ ) measures the light that is reflected directly from the surface of a fruit while diffuse reflectance (Figure 4c) measures light reflected at multiple angles from the surface. Interactance (Figure $4 \mathrm{~d}$ ) measures light that has scattered underneath the surface and returned to the fruit surface and is a better representation of what is going on internally.

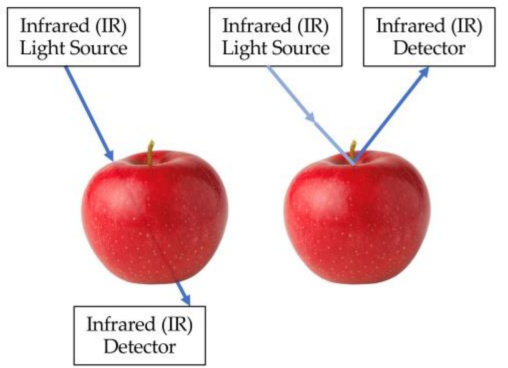

(a) (b)

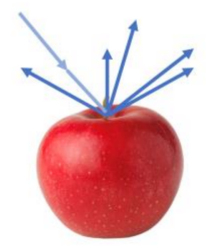

(c)

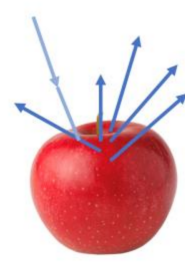

(d)

Figure 4. NIR Spectroscopy Configurations [59]. (a) transmittance; (b) reflectance; (c) diffuse reflectance; and (d) interactance.

Unlike other sensor technologies used to estimate the sugar content of fruit and fruit juice, results of NIR studies often report their results in terms of $R, R^{2}, S E P$ and RMSEP (Table 5).

$R$ is the correlation coefficient. $R^{2}$ is the coefficient of determination which indicates how much variation in the NIR method is attributed to actual variation in the parameter being measured as established by calibration with an accepted reference such as Fourier transform infrared spectroscopy (FTIR). For example, an $R^{2}$ value of 0.98 indicates that $2 \%$ of the variation in a set of NIR measurements comes from error while the remaining variation comes from actual changes in the parameter being measured (e.g., total sugar content). RMSEP is the root mean square error of prediction and represents the average uncertainty that can be expected when evaluating samples outside of the calibration set (i.e., new samples). For detecting total sugar content, the accuracy of any future prediction of sugar content is then within +/ - twice the RMSEP. SEP, on the other hand, measures the precision of the prediction or the amount that a future concentration will vary when making the same measurement multiple times (i.e., repeated measurements). Using these metrics, a wide range of fruits and fruit juices have been evaluated, often with $\mathrm{R}^{2}$ values above 0.90 and prediction errors of less than 1 when measuring total sugars, soluble solids content (SSC) as a proxy for total sugars, and ${ }^{\circ}$ Brix (Table 5). 
Table 5. NIR Spectroscopy for Measurement of Sugar Content in Fruit and Fruit Juice. NS: Not Studied; SEP: Standard Error of Prediction; RMSEP: Root Mean SEP.

\begin{tabular}{|c|c|c|c|c|c|}
\hline Study & Approach & Type & Unit & $R$ or $R^{2}$ & SEP or RMSEP \\
\hline \multicolumn{6}{|c|}{ Intact Fruits } \\
\hline [60] & reflectance & apples & ${ }^{\circ}$ Brix & $\mathrm{R}^{2}=0.94$ & $\mathrm{SEP}=0.97$ \\
\hline$[61]$ & diffuse reflectance & apple, peeled & ${ }^{\circ}$ Brix & $R=0.93-0.97$ & $\mathrm{SEP}=0.37-0.42$ \\
\hline$[62]$ & transmittance & orange (mandarin) & $\mathrm{SSC}^{1}$ & $\mathrm{R}=0.93$ & RMSEP $=0.65$ \\
\hline$[63]$ & reflectance & orange (mandarin) & $\mathrm{SSC}^{1}$ & $\mathrm{R}^{2}=0.93$ & RMSEP $=0.32$ \\
\hline [64] & reflectance & orange, navel & $\mathrm{SSC}^{1}$ & $\mathrm{R}=0.90$ & RMSEP $=0.68$ \\
\hline$[65]$ & reflectance & grapefruit, red & $\operatorname{SSC}^{1}$ & $\mathrm{R}^{2}=0.67$ & NS \\
\hline$[66]$ & diffuse reflectance & jujube & TS $^{3}$ & $\mathrm{R}=0.904$ & RMSEP $=0.26$ \\
\hline$[67]$ & interactance, transmittance & passion fruit & $\operatorname{SSC}^{1}$ & $\mathrm{R}=0.92$ & NS \\
\hline$[68]$ & transmittance & pear & $\mathrm{SSC}^{1}$ & $\mathrm{R}^{2}=0.87$ & RMSEP $=0.45$ \\
\hline$[69]$ & diffuse reflectance & strawberry & $\mathrm{SSC}^{1}$ & $\mathrm{R}^{2}=0.94$ & RMSEP $=0.29$ \\
\hline \multirow{2}{*}[70]{} & interactance & \multirow{2}{*}{ umbu fruit } & $\mathrm{SSC}^{1}$ & $\mathrm{R}^{2}=0.78$ & RMSEP $=0.72$ \\
\hline & reflectance & & $\mathrm{SSC}^{1}$ & $\mathrm{R}^{2}=0.61$ & RMSEP = 1.02 \\
\hline \multicolumn{6}{|c|}{ Fruit Juice } \\
\hline [71] & reflectance & orange & SSC $^{1}$ & $\mathrm{R}=0.98$ & RMSEP $=0.73$ \\
\hline
\end{tabular}

${ }^{1}$ Soluble solids content used as an estimate for total sugar content. ${ }^{2} \mathrm{R}$ squared (coefficient of determination). ${ }^{3}$ Total sugar content.

\section{Sensing Technologies for Acidity (pH)}

$\mathrm{pH}$ sensors can be broken down into a number of categories: (a) zero power, lowresolution papers and strips; (b) glass electrodes and other electrochemical sensors; (c) higher-cost optical instruments; and (d) other electrical and electromechanical sensor technologies which have the potential to be commercialized as low-cost, portable alternatives to existing $\mathrm{pH}$ sensors on the market. At the time of this writing, the vast majority of commercialized $\mathrm{pH}$ sensors belong to categories (a) and (b). As with sugar content (sweetness) sensors, $\mathrm{pH}$ sensing technologies require that the fruit sample be liquid, either as fruit juice or as a mash of the intact fruit. Most existing $\mathrm{pH}$ sensors require destruction of the fruit to prepare a suitable liquid sample to determine $\mathrm{pH}$. Microextraction of solid samples from firm fruits (e.g., apples) or the juice internal to softer fruit (e.g., tomatoes) would enable $\mathrm{pH}$ to be detected non-destructively, but techniques to do so are limited and not widely commercially available.

\subsection{Traditional $p H$ Sensors (Papers and Strips)}

The oldest and most inexpensive $\mathrm{pH}$ sensors are the litmus indicators, the first of which were extracted from lichens that turn red when exposed to an acid and blue when exposed to a base. Commercial indicators that are relevant to monitoring fruit acidity include methyl red, methyl orange, and bromocresol green which offer color transitions within a $\mathrm{pH}$ unit of 5.1, 3.7, and $4.7 \mathrm{pH}$ units, respectively [72]. These indicators offer coarse $\mathrm{pH}$ measurements at resolutions of $1.0 \mathrm{pH}$ units or greater across a narrow range of $\mathrm{pH}$. While $1 \mathrm{pH}$ unit may be sufficient to differentiate an unripe fruit from a ripe one, greater resolution is necessary to make the kinds of distinctions necessary to monitor acidity relevant to fruit flavor and overall fruit quality at the point of harvest and beyond.

\subsection{Glass Electrodes for Measuring $p H$}

A widespread, higher resolution, commercial alternative to sense $\mathrm{pH}$ is the glass electrode (Figure 5a). The glass electrode works by using an electrochemical cell to measure the concentration of hydrogen ions in solution. Hydrogen ions in solution interact with a 
solid material, called a working electrode, to either extract electrons or impart electrons to the electrode. The number of electrons that are exchanged between the solution and the working electrode depends on the concentration of hydrogen ions in the solution. $\mathrm{pH}$ can be calculated from the hydrogen ion concentration using the following relationship:

$$
p H=-\log _{10}\left(\left[H^{+}\right]\right)
$$

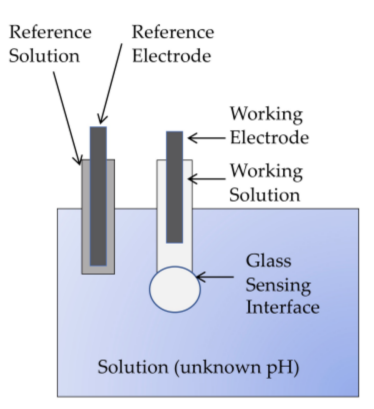

(a)

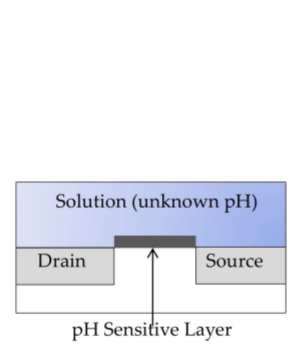

(b)

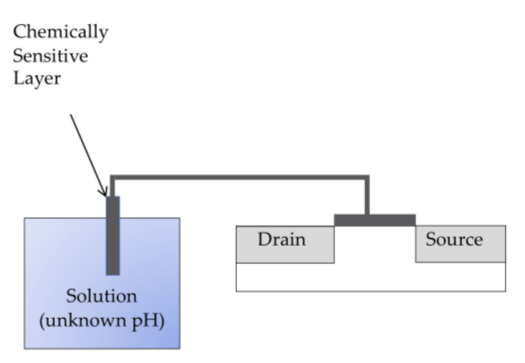

(c)

Figure 5. Electrochemical pH Sensors. (a) Traditional, glass electrode-based pH sensing; (b) ISFETbased $\mathrm{pH}$ sensing, where the gate of a field effect transistor (FET) is removed and is replaced by the interaction of solution and $\mathrm{pH}$-sensitive layer to modulate the current between the drain and source of the transistor; and (c) extended gate FET (EGFET), which separates the electronic half of the ISFET from the electrochemically sensitive half in order to extend sensor lifetime and reduce drift.

Another electrode in the system, the reference electrode, provides a stable reference point to the electrochemical cell in a manner that is similar to a signal ground in an electrical circuit. A stable equilibrium is maintained between the reference electrode and the electrolyte surrounding it by design. In this way, the resulting potential difference between working and reference electrode provides a reliable and stable indicator of the accumulation or extraction of electrons by hydrogen ions at the working electrode (i.e., $\mathrm{pH}$ ).

A typical electrochemical $\mathrm{pH}$ electrode measurement system uses an $\mathrm{Ag} / \mathrm{AgCl}$ (silver/silver chloride) reference electrode in a constant $\mathrm{pH}$ solution as the reference electrode and reference solution, respectively. This establishes the reference potential. A glass electrode coated with a hydrated gel then serves as the working electrode, and the potential across the two electrodes (reference and working) is given by the Nernst equation:

$$
V=V_{o}-\frac{2.3 R T}{n F}(p H)
$$

where $R$ and $F$ are constants, $n$ is constant for a given type of electrode or $\mathrm{pH}$ sensor, $T$ is temperature in degrees Kelvin, $V_{\mathrm{o}}$ is a constant that depends on the reference electrode, and $p H$ is the unknown $\mathrm{pH}$ in the liquid sample.

Glass electrode $\mathrm{pH}$ measurement systems are commercially available from a range of vendors including Hach, Fisher Scientific, Cole-Parmer, Hanna Instruments, and Mettler Toledo and range in cost between $\$ 100$ and $\$ 500$ USD. Glass electrodes are fragile, relatively large, and require frequent recalibration which limit their use for farm-to-table operations. Regardless, among the possible approaches to measuring $\mathrm{pH}$, the glass electrode has been the most successful commercially and is likely to be a candidate in any agricultural application that requires accurate and reliable measurements of $\mathrm{pH}$.

\subsection{Other Electrochemical Approaches to $\mathrm{pH}$ Measurement}

Over several decades of research, various possibilities for miniaturizing electrochemical sensors have been investigated as compact, low-cost, robust alternatives to the glass electrode [73]. Miniaturizing $\mathrm{pH}$ sensors is a critical step for enabling these sensors to be used in many of the harvesting, transport, and storage processes in farm-to-table operations. The most promising option for miniaturizing the glass electrode is the ISFET (ion-sensitive 
field effect transistor) shown schematically in Figure 5b. In a pH-sensitive ISFET, the gate of the transistor is removed and the underlying insulator layer interacts with the liquid sample, either accumulating additional electrons or losing electrons in doing so. Much like the working electrode in the conventional glass electrode, the resulting charge on the insulator layer is proportional to the concentration of hydrogen ions in and $\mathrm{pH}$ of the solution in a manner that follows the Nernst equation (Equation (4)). Similar to the operation of a standard MOSFET in computer chips, the charge on the insulator layer then modulates the current travelling along the channel of the transistor (between drain and source), increasing as hydrogen ion concentration in solution increases. Silicon dioxide and silicon nitride are two common choices for the insulator layer in an ISFET and are particularly attractive for low-cost $\mathrm{pH}$ sensors because they are compatible with established integrated circuit fabrication processes and as a result, are low-cost and easily mass-produced.

Despite initially emerging in the scientific literature in the 1970s, the ISFET was not commercialized until the 1990s because irreversible reactions with the insulator layer make the devices vulnerable to drift. Sensitivity to both light and temperature further compromises ISFET performance. Further, like the glass electrode, the ISFET requires a reference electrode which is both fragile and difficult to miniaturize. In spite of these limitations, some $\mathrm{pH}$ ISFETs are commercially available (e.g., through Emerson, ThermOrion, Honeywell, and Sentron) and are suitable for monitoring fruit quality at various stages from the point of harvest through post-harvest processing and transport. However, the cost of these ISFET devices remains relatively high and limits their practical use in farm-to-table applications.

The reference FET (REFET) provides an alternative to the traditional reference electrodebased electrochemical cell by using two ISFET structures. The first ISFET is $\mathrm{pH}$ sensitive and the second is not, thereby providing a reference point for $\mathrm{pH}$ measurements [74]. Unfortunately, REFETs demonstrated to date have been hampered by a short lifetime that prevents their commercialization. Another modification of the basic ISFET structure is the extended gate FET (EGFET) which separates the electrical and the chemical components of the ISFET system (Figure 5c) to preserve the lifetime of the electronics, promote stability, and limit drift [75]. For high resolution, dual-gate ISFETs [76] use two gates rather than one. Manipulation of the capacitance associated with one gate vs. that associated with the second gate on the dual-gate FET has successfully and dramatically increased the Nernstian limited sensitivity of $59 \mathrm{mV} / \mathrm{pH}$ unit associated with other $\mathrm{pH}$ sensors. At this time, however, difficulties in commercializing these ISFET alternatives have made miniaturizing the traditional reference electrode design the most lucrative among the electrochemical alternatives to the glass electrode. MicroSens makes an integrated ISFET-based $\mathrm{pH}$ sensor using such a miniaturized electrode [77].

A wide range of electrochemical approaches to measuring $\mathrm{pH}$ are available at an equally wide range of costs and all with limitations. These approaches are summarized in Table 6. Note that a $\mathrm{pH}$ range between 2 and 7 is suitable for monitoring the acidity of fresh fruit.

Table 6. Electrochemical Sensors for Measuring pH. NS: not specified; NC: not commercialized; NA: not applicable.

\begin{tabular}{|c|c|c|c|c|c|}
\hline Technology & $\begin{array}{c}\text { Sensitivity } \\
(\mathrm{mV} / \mathrm{pH})\end{array}$ & $\begin{array}{l}\text { Resolution } \\
\text { (pH Units) }\end{array}$ & $\begin{array}{c}\text { Range } \\
\text { (pH Units) }\end{array}$ & $\begin{array}{c}\text { Cost } \\
\text { (USD) }\end{array}$ & Ref \\
\hline $\mathrm{pH}$ strips & NA & 1 & $0-14$ & $\$ 0.02$ & \\
\hline glass electrode & NA & 0.001 & $-2-16$ & $\$ 400^{1}$ & [78] \\
\hline cloth junction & NA & 0.1 & $0-14$ & $\$ 75^{1}$ & [79] \\
\hline ISFET & 33 & Varies $^{2}$ & $4-10$ & $\mathrm{NC}$ & [80] \\
\hline $\begin{array}{l}\text { ISFET with miniaturized } \\
\text { reference electrode }\end{array}$ & 55 & Varies $^{2}$ & $2-11$ & NS & [81] \\
\hline REFET & 50 & Varies $^{2}$ & $1-14$ & $\mathrm{NC}$ & [82] \\
\hline EGFET & 50 & Varies $^{2}$ & $7-12$ & $\mathrm{NC}$ & [83] \\
\hline EGFET & 28 & Varies $^{2}$ & $2-12$ & $\mathrm{NC}$ & [84] \\
\hline dual-gate ISFET & 304 & Varies $^{2}$ & $3-10$ & $\mathrm{NC}$ & [85] \\
\hline
\end{tabular}

${ }^{1}$ Includes calibration bundle. ${ }^{2}$ Resolution depends on resolution of interface circuits or analog to digital converter. 


\subsection{Electrical Approaches to $\mathrm{pH}$ Measurement}

An alternative to electrochemical sensing of $\mathrm{pH}$ is the direct conversion of $\mathrm{pH}$ to electrical resistance or conductivity. This approach to sensing has the potential to be compact, low-cost, and low power. $\mathrm{pH}$ sensitive, conducting polymers include polyaniline or PANI [86] are sensitive to the $\mathrm{pH}$ ranges associated with fruit quality. Instability in sensor output associated with these films when used as $\mathrm{pH}$ sensors can be addressed through the addition of other polymers such as polypyrrole [87]. Some metal oxides are also suitable for sensing $\mathrm{pH}$. For example, ruthenium oxide deposited on an interdigitated silver electrode experiences a decrease in resistance with increasing $\mathrm{pH}$ in a range between 3 and $11 \mathrm{pH}$ units [88]. Titanium monoxide is also sensitive to $\mathrm{pH}$ in solution, but poor repeatability makes this material suitable only for coarse or single use measurements [89]. At low frequencies, different types of tin oxide films also show a decrease in conductance with increasing $\mathrm{pH}$ in the range of $2-11 \mathrm{pH}$ units [89]. While these conductance- or resistancebased measurements are noisy and likely to offer lower resolution than electrochemical sensors, they nevertheless offer a level of simplicity that could enable sufficiently low-cost manufacturing to support monitoring $\mathrm{pH}$ in individual fruit. If sufficiently small amounts of juice (or fruit mash) allowed for an adequate sample, non-destructive evaluation of $\mathrm{pH}$ in fruit would also be possible.

\subsection{Electromechanical Approaches to $\mathrm{pH}$ Measurement}

$\mathrm{pH}$ can also be measured using electromechanical techniques which involve converting a change in $\mathrm{pH}$ to a change in one or more mechanical properties of the sensor such as bending, mass, shape, or elasticity. One of the most popular approaches to extract $\mathrm{pH}$ using electromechanical sensors is the micro or nanoscale cantilever beam. In this type of sensor, the beam is coated with a material that bends in response to changing $\mathrm{pH}$ in the ambient environment. The bending of the beam is then read using the capacitive, resonance, or piezoresistive properties of the accompanying sensor.

Hydrogels are an attractive coating for cantilever beams. They undergo significant conformal changes in shape and size in response to $\mathrm{pH}$ changes. A hydrogel is a polymer (plastic) that contains molecular chains which are cross linked into a 3D matrix. In the first phase of the hydrogel's response to a solution, the hydrogel is at its most hydrophobic (i.e., repelled from water) and shrinks. In the second phase, the hydrogel tries to mix with the solution in which it is immersed, thus causing it to expand or swell at maximum hydrophilicity (i.e., attraction to water). Fortuitously, some hydrogels experience this transition at a point that is dependent on $\mathrm{pH}$ [90]. When bonded to a cantilever beam for signal detection, the large changes in shape of the hydrogel—up to 100 fold in response to small changes in $\mathrm{pH}$, can compete with the sensitivity of electrochemical sensors. Hydrogelbased $\mathrm{pH}$ sensors using cantilever beam technology have demonstrated sensitivities on the order of $10^{-5} \mathrm{pH}$ units [90]. However, this high sensitivity comes at a price because the limited motion of tiny cantilever beams limits the dynamic range of the resulting $\mathrm{pH}$ sensor. For broader dynamic range, albeit at lower sensitivity, other $\mathrm{pH}$-sensitive materials such as silicon nitride and silicon oxide can be deposited on microcantilevers to detect $\mathrm{pH}$ [91]. Although other structures such as diaphragms are available to facilitate this type of sensing approach, the microcantilever beam is both compatible with conventional microfabrication processes and highly sensitive to small changes in the beam properties. While the use of a cantilever beam may seem unnecessarily complex for measuring $\mathrm{pH}$, this approach has been successfully used in a wide range of accelerometer designs at low cost. Thus, arrays of hydrogel coated beams are an option for high-sensitivity $\mathrm{pH}$ sensors and beams coated with silicon nitride or silicon oxide offer a less-sensitive but low-cost solution that can capitalize on existing commercial MEMs (microelectromechanical systems) fabrication processes.

Unfortunately, electromechanical systems can be limited by their ability to detect motion of the cantilever beam or other mechanical structure using piezoresistive or capacitive means. Alternatively, coupling the mechanical signal to an optical rather than electrical signal can offer much higher detection limits. Such nano-optomechanical systems 
can achieve motion detection limits on the order of femtometers and can enable single molecule detection in liquids [92]. While these optomechanical sensors offer the small size appropriate for sensing $\mathrm{pH}$ while fruit are in storage or in transport, their cost may not be compatible with the small volume applications that are typical of farm-to-table operations. Nevertheless, they offer a viable alternative to electromechanical means for measuring $\mathrm{pH}$ and future advances in sensor development may significantly reduce the costs associated with this approach.

\subsection{Optical Approaches to $\mathrm{pH}$ Measurement}

In addition to measuring $\mathrm{pH}$ optically via the mechanical motion of a $\mathrm{pH}$-sensitive element, $\mathrm{pH}$ can also be measured indirectly with other optical techniques. For example, a $\mathrm{pH}$-sensitive dye can be immobilized in a solid material or matrix that is designed so that the protons or hydronium ions that are indicative of $\mathrm{pH}$ can be measured via $\mathrm{RI}$ (refractive index). Using $\mathrm{RI}$ as an indicator of $\mathrm{pH}$ has some advantages. While conventional $\mathrm{pH}$ color strips produce a $\mathrm{pH}$-sensitive color that can be measured with the naked eye, the eye can be inconsistent, unreliable, and imprecise. More precise measurements of color require a colorimeter to precisely measure the absorption of light by different colors or a spectrophotometer to measure the transmittance or reflectance of light associated with a color strip. This usually makes the resulting instruments expensive. In contrast, RI can be measured electronically and precisely at much lower cost (Table 4) than color.

Another optical approach to detecting $\mathrm{pH}$ involves using materials which are both $\mathrm{pH}$ sensitive and which exhibit fluorescence. Fluorescent $\mathrm{pH}$ dyes work by absorbing light across a relatively wide range of colors or wavelengths and re-emitting that light at a different and distinct color. Fluorescence intensity typically changes with $\mathrm{pH}$, although some fluorescent dyes change in phase or color in response to $\mathrm{pH}$. $\mathrm{pH}$-sensitive, fluorescent dyes offer higher resolution than many other techniques and operate over ranges compatible with fruit [93], but they contaminate samples during measurement which eliminates any possibility of non-destructive evaluation of intact fruit.

Also complicating optical $\mathrm{pH}$ sensing approaches is the fact that light signals must be subsequently converted to an electrical signal. Adding an accurate photodiode or other photodetector to these systems adds overhead, power consumption, and cost to the overall instrument. Despite the increased overhead, optical pH detection is more stable and less vulnerable to interference than other techniques.

\section{Sensing Technologies for Ethylene}

The presence of ethylene gas in the ambient environment can influence fruit ripening at levels as low as tens of $\mathrm{nL} / \mathrm{L}$ [94]. During the ripening of a climacteric fruit such as the tomato, ethylene production can increase as much as 20 fold before starting to decline as the fruit over-ripens and degrades. Daily changes in internal ethylene concentration of tomatoes from ripening fruit are on the order of $100 \mathrm{~nL} / \mathrm{L}$ [95]. Determining the optimal ripening point for harvest in farm-to-table operations depends on how far the fruit must travel to reach the point of consumption as well as the conditions under which it will be processed and transported. If these things are known, measuring the rate of change of ethylene concentration and the direction of change can play a critical role in optimizing the time of harvest and maximizing yield. Unlike conventional agriculture, ambient ethylene concentration is not artificially manipulated in farm-to-table operations because the delay between harvest and consumption is much shorter. Thus, fruits can be harvested when they are almost at peak ripeness rather than well before they have fully matured. This allows for fresher, more nutrient rich, and higher quality fruit to reach the consumer. Further, while ethylene sensors are useful at the point of harvest to monitor the rate of change of ethylene production and accurately identify the ripening stage of fruit, they are also useful post-harvest. After a fruit has been picked, it is likely to be boxed with companion fruit and produce of other types in shipments direct to the consumer. This can trigger ethylene-sensitive fruits (Table 3) to begin ripening faster than normal, risking premature 
spoilage. Therefore, post-harvest, ethylene sensing may be reduced to threshold sensors which trigger an alarm only when one or more thresholds of ethylene sensitivity have been reached. These thresholds depend on the type of fruit or vegetables shipped in close proximity to one another. Threshold-based ethylene sensors that are triggered at higher concentrations open up possibilities for low-cost, single-use, and low or zero-power sensors to support fruit quality throughout post-harvest processing.

Four sensing technologies presently dominate ethylene gas sensing in agriculture and food distribution: photoacoustic spectroscopy, gas chromatography, non-dispersive infrared spectroscopy (NDIR), and electrochemical sensing. Each approach offers limits of detection in the parts per billion ( $\mathrm{ppb}$ ) range but with unique pros and cons that limit their use in farm-to-table operations. These four primary sensing technologies are discussed next, followed by a look at other chemical sensors that may offer lower-cost options.

\subsection{Photoacoustic Spectroscopy}

Photoacoustic spectroscopy uses a microphone in a controlled testing chamber to measure pressure changes that follow temperature shifts incurred when infrared light from a laser is absorbed by a gas of interest inside the chamber. For ethylene, a $\mathrm{CO}_{2}$ laser with emission at $10,600 \mathrm{~nm}$ is an excellent match to ethylene gas. Ethylene actively absorbs IR light around this wavelength [96]. The laser light source is both polarized (vibrating in a single plane) and chopped (turned on and off) so that the photoacoustic signal can be measured with high precision. Under controlled laboratory conditions using gas lasers, ethylene gas concentrations as low as 6 parts per trillion (ppt) have been measured [97]. Field measurements of ethylene gas using photoacoustic spectroscopy have not surprisingly demonstrated limits of detection that are not as good as laboratory results. Nevertheless, detection limits compatible with fruit quality monitoring are possible. In the field, photoacoustic spectroscopy using gas lasers has detected ethylene gas between 18.7 and $40.3 \mathrm{ppb}$ [98] and between $0.6 \mathrm{ppm}$ and $47 \mathrm{ppm}$ [99] when applied to monitoring air pollution. Using a smaller, less power-hungry $(0.3 \mathrm{~mW})$ semiconductor laser, ethylene has been detected at $30 \mathrm{ppm}$ [100]. Further, using quartz enhanced photoacoustic spectroscopy in combination with low power semiconductor lasers has allowed limits of detection as low as $300 \mathrm{ppb}$ [101]. Advances in the use of semiconductor lasers for photoacoustic spectroscopy have led to the commercialization of mobile ethylene detectors with detection limits in the hundreds of $\mathrm{ppb}$. However, these instruments are expensive (tens of thousands of dollars), power hungry (100 W), and heavy (13 kg) [102]. Even less-sensitive photoacoustic spectroscopy instruments suitable for detecting levels of ethylene in farm-to-table operations are far too expensive and bulky. Photoacoustic sensors are also inherently sensitive to noise and vibration in the ambient environment as well as temperature and humidity changes in the gas under test [32]. These vulnerabilities further detract from their appeal as portable instruments for monitoring ethylene gas production and absorption by fruit.

\subsection{Gas Chromatography}

Gas chromatography is another popular and viable approach for detecting ethylene gas. While not a sensing method in and of itself, gas chromatography serves a key function in ethylene gas sensing by separating ethylene from other gases in a sample in order to reduce interference from other similar gases. Once gases are separated by the gas chromatograph, their concentration can be sensed using a variety of methods of which flame ionization detectors (FID), thermal conductivity detectors (TCD), electrochemical sensors, and mass spectroscopy are among the most common. A gas chromatograph uses a carrier gas which is either inert (e.g., helium) or unreactive (e.g., nitrogen) to transport a sample (of gas or vapor) into a column where it interacts with a liquid or polymer in the column. Different gases are eluted (released) from the column at different times so that the detector at the back end of a gas chromatographic system must only sense one gas at any given time. In combination, the time after introduction of the gas to the chromatograph and 
the sensor (or detector) output determine the type and concentration of the gas, respectively. Automated samplers available for commercialized systems also offer a level of repeatability in measurements that is not possible with manual introduction of sample gases to gas chromatography systems [94].

Multiple detector technologies are available to support gas chromatography. Flame ionization detection (FID) works by mixing the carrier gas (and eluted gases) from the gas chromatography column with hydrogen and burning them in a flame. Approximately one in 10,000 molecules from the gas of interest in the burning process creates a gasphase ion which is collected by an electrode that is placed above the flame. The resulting current is highly sensitive and proportional to the concentration of ethylene or other gas of interest. The thermal conductivity detector (TCD) works by monitoring the temperature of a hot filament as the carrier gas and eluted gas from the gas chromatograph pass by the filament. Since the carrier gas and eluted gas have different thermal conductivities, the temperature of the filament will change depending on the proportion of eluted gas in the sample [103]. Temperature changes can be sensed with high precision, resulting in a highly sensitive gas sensing mechanism. When mass spectroscopy is used as the detector in a gas chromatography system, the sample (carrier gas + eluted gas) is ionized by bombarding it with electrons and then separated according to mass-to-charge ratio of the two gases by accelerating them and deflecting them through an electric or magnetic field. Charged particles with the same mass to charge ratio will be deflected similarly and can be collected by a device such as an electron multiplier. Since the amount of deflection is related to the mass of the gas, the mass spectrometer provides further selectivity in ensuring at any given time and at any given detector in the sensing system, only one gas is sensed at a time [103]. In summary, gas chromatographs paired with any of these three forms of detection can be highly sensitive and highly selective to ethylene. However, these systems are also large and complex, consume significant power, and are very expensive. Thus, while traditional gas chromatography systems are well suited for precise analysis and modelling of fruit ripening, they are poorly suited to the cost and power constraints faced by small farms and small businesses involved in farm-to-table operations.

The miniaturization of gas chromatography systems, however, offers some hope for their use in monitoring fruit ripening and fruit quality. Miniaturization of the column used in gas chromatography inherently reduces the sensitivity of the column as less surface area is available to capture and release gases of interest. To improve sensitivity in these miniaturized systems, a pre-concentrator amplifies the concentration of gases of interest to enhance the overall sensitivity of the gas chromatography system [104]. Pre-concentration can improve the limit of detection of ethylene detection systems from $140 \mathrm{ppm}$ to $6 \mathrm{ppm}$ [105] and 1 ppm [106]. However, preconcentration also introduces humidity, which impairs the accuracy and limit of detection for these systems. Despite these limitations, recent advances in the use of micromachining to construct three dimensional GC columns have demonstrated limits of detection for ethylene gas in banana monitoring of $35 \mathrm{ppb}$ [107] and a resolution of $12 \mathrm{ppb}$ using metal oxide detectors [108]. These performance levels are compatible with monitoring both ethylene gas concentrations and rates of change in these concentrations relevant to monitoring fruit ripening and degradation. However, even miniaturized systems are expensive and cost prohibitive for many small farms and businesses. But, the ultra-sensitivity of nano-optomechanical systems at the detector (back-end) of GC systems has the potential to replace preconcentration while still providing ppm level sensitivity for volatile organic compounds and also enabling miniaturized and low-cost systems for ethylene sensing [109].

\subsection{Non-Dispersive Infrared Spectroscopy (NDIR)}

In contrast to gas chromatography and photoacoustic spectroscopy, non-dispersive infrared (NDIR) spectroscopy can analyze and detect gases with far fewer stages of detection and lower overall complexity. NDIR offers great promise for portable and low-cost sensing applications. Infrared spectroscopy is already a familiar part of agricultural operations 
and has been demonstrated for a wide range of uses including detecting adulterants in beef products [110] and wine, olive oil, and fruit juice [111], pesticide residues in strawberries [112], moisture in grains, protein, oil, and soybeans, and quality of spices, teas, medicinal plants, fruits, vegetables and dairy products [113]. NDIR sensors are some of the simplest spectroscopic sensors because they do not require specialized optics such as prisms or diffraction gratings to disperse or separate incoming light to the sensor.

NDIR sensors operate in one of two ways. In one configuration, an infrared light source is paired with an optical filter to select a narrow band of incoming IR light. The light is then transmitted through a gas sample in a light tube to an infrared photodetector. The light source and optical filter are selected to transmit light that is absorbed by the gas of interest. Incoming light is also chopped (turned on and off) or otherwise modulated to reduce interference from heating effects caused by the light source itself. Ethylene absorbs infrared light well at 10,600 nm, which makes it compatible with this form of NDIR sensing. However, ethylene is not the only gas that absorbs infrared light at this wavelength and interference from carbon dioxide and other gases commonly found in air can compromise the accuracy of this type of NDIR configuration. A second NDIR configuration uses multiple infrared detectors each of which evaluates IR light absorption at a different band of wavelengths in order to reduce the effect of interference. NDIR sensor systems of this type have been successfully demonstrated to detect ethylene at a limit of detection of 5 ppm [32]. Commercially available systems using this approach to NDIR sensing detect ethylene at limits of detection on the order of 20 ppm [114]. Pre-concentrators are also an option to improve the limit of detection and have demonstrated 40-fold improvements in performance [115]. NDIR systems have been successfully demonstrated in monitoring the artificial ripening of fruit with 5 ppm detection limits [116], thus underscoring their suitability in both performance and footprint to detecting ethylene for monitoring fruit quality. While NDIR limits of detection and resolution have room for improvement, the simplicity, low cost, and inherent stability of this optical sensing technique is one of the most promising opportunities for monitoring ethylene in farm-to-table operations.

\subsection{Electrochemical Sensors}

Traditional electrochemical sensors produce one of two types of electrical outputs: a current or a voltage. When the output of the sensor is a voltage, the sensor typically draws no current and its operation is labelled potentiometric. The voltage across the potentiometric electrochemical sensor is linear and a Nernstian function of the concentration of the analyte of interest (e.g., the pH sensor of Equation (4)). For example, an ethylene electrochemical sensor made with a $\mathrm{Fe}_{0.7} \mathrm{Cr}_{1.3} \mathrm{O}_{3}$ working electrode and a solid electrolyte has been demonstrated for measuring ethylene at high temperatures in diesel exhaust [117]. Ethylene was detected at levels down to $50 \mathrm{ppm}$ for this potentiometric sensor with a Nernstian sensitivity of $0.12 \mathrm{mV} / \mathrm{ppm}$. A level of $50 \mathrm{ppm}$ is too high a detection limit for monitoring fruit quality and potential degradation. Unfortunately, these relatively high detection limits are only one problem associated with a potentiometric approach to measuring ethylene. Potentiometric sensors have limited selectivity. For example, the $\mathrm{Fe}_{0.7} \mathrm{Cr}_{1.3} \mathrm{O}_{3}$-based diesel exhaust sensor demonstrated in [117] was also sensitive to carbon monoxide (CO) at $0.024 \mathrm{mV} / \mathrm{ppm}$. CO is present in high concentrations in diesel exhaust thus making a 5:1 selectivity ratio impractical for sensing ethylene in these applications. Similar problems in selectivity are encountered in monitoring fruit quality because of interference from ethanol and other fruit metabolites. Further, humidity can have a dramatic effect on the performance of electrochemical gas sensors in potentiometric operations, producing $20 \%$ differences in sensor sensitivity between dry and wet conditions [117]. Thus, despite the stability and predictability of potentiometric electrochemical sensors, their vulnerability to interference from related gases and from humidity often compromises their candidacy for measuring ethylene in agricultural applications.

Unlike potentiometric operation, the amperometric operation of electrochemical sensors produces a current that reflects the concentration of an analyte of interest in the sensing 
environment. This current flows from counter to working electrode in the electrochemical cell or vice versa. Drawing current between the electrodes in an electrochemical sensor improves sensitivity, lowers the limit of detection, and overcomes selectivity issues associated with potentiometric sensors. Amperometric electrochemical sensors for detecting ethylene gas have been implemented using ionic liquid as the electrolyte between electrodes for a limit of detection of $760 \mathrm{ppb}$ [118] and using a compact, three-electrode measurement system that includes a micropump for circulating ambient air over the sensing electrode to sense ethylene down to $100 \mathrm{ppb}$ [119]. While these limits of detection are attractive for ethylene monitoring during fruit ripening as well as during post-harvest processing and transport, this approach has significant drawbacks. For ethylene, acid electrolytes are often used in conjunction with gold working electrodes to prevent gold oxide from forming before ethylene can oxidize the electrode; acid toxicity and corrosion are undesirable for portable instruments and limit sensor and instrument lifetime. Further, when ethylene oxidizes a working electrode, it produces interfering gases which can compromise the overall selectivity of the sensor and further shorten its lifetime [94]. Amperometric operation also consumes electrode material and electrolyte which leads to drift and stability problems in sensor performance. Thus, in practical terms, stability, degradation, and lifetime issues in amperometric sensors and the poor selectivity of potentiometric sensors must still be addressed in order to make electrochemical sensors viable alternatives for sensing ambient and internal ethylene in fruit.

\subsection{Other Chemical Sensors}

Electrochemical sensors are distinctive from other sensors which convert chemical information directly to electrical information in that they involve oxidation and reduction reactions with conductive electrodes to generate a current or voltage indicative of chemical concentration. Electrochemical sensor systems require two and sometimes three electrodes to ensure stable, drift-resistant operation. These requirements increase the size and cost of the overall instrument. Other means for directly converting chemical information to an electrical parameter are possible. For example, a chemiresistor converts chemical information directly to a change in conductance or resistance via reactions with a gas of interest in the ambient environment. Metal-oxide semiconductors are particularly attractive for use as chemiresistors because their baseline resistance is low compared to other materials and they are sensitive to a wide range of reducing gases. In a metal-oxide chemiresistor (Figure 6), reducing gases, including ethylene, interact with oxygen on the surface of the semiconducting metal oxide, thereby causing electrons to be re-injected into the bulk semiconductor and increasing conductivity (decreasing resistance).

Tin oxide $\left(\mathrm{SnO}_{2}\right)$ is a common n-type semiconductor used for many decades in gas sensing. Tungsten oxides [120] and iron oxides [121] are also sensitive to ethylene gas but without modification exhibit lower sensitivity and less favorable detection limits than tin oxide-based sensors. Regardless of the type of metal oxide used in these gas sensors, the circuits and interfaces required to measure subsequent changes in resistance are simple and offer the possibility for low-cost, compact, and perhaps even single-use ethylene sensors. However, unmodified metal oxide semiconductors are limited in detection limit and sensitivity by their surface-to-volume ratio, are broadly selective to a range of reducing gases, and drift over time as a result of irreversible reactions with the exposed surface. Significant research attention has been directed at improving these three performance limitations. For example, the addition of catalysts to metal-oxide gas sensors increases selectivity to certain gases over others. For example, adding palladium (Pd) nanoparticles as a catalyst to tin oxide-based gas sensors has been shown to increase the ethylene response of these sensors by a factor of 3X while providing detection limits as low as $50 \mathrm{ppb}$ [122]. The use of heterostructures can also improve sensor performance. For example, cerium oxide-tin oxide nanocomposite heterostructures can increase sensor response to ethylene gas by a factor of 5 or more and reduce the detection limit from ppm to sub-ppm levels [120]. Further, nanoparticles and nanostructures offer increased surface area as a percentage of 
overall sensor volume for increased sensitivity and lower detection limits. Tin oxide nanoparticle sensors enhanced with palladium respond to ethylene concentrations in the tens of ppm [123]. Carbon nanotubes offer even higher surface-to-volume ratios than nanoparticle-based gas sensors by facilitating the adsorption of gas molecules (including ethylene) on both the interior and exterior of their hollow tubelike structures. Copper ligands have been mixed with single walled nanotubes (SWNTs) to fabricate highly stable ethylene sensors with sub-ppm detection limits and a selective response to ethylene over other fruit metabolites-a 3-fold response compared to acetaldehyde and 8-fold response compared to ethanol [124]. Other carbon nanotube-based gas sensors are based on Wacker oxidation that does not require the binding of copper to ethylene but instead uses a palladium catalyst to enhance the oxidation process and increase the conductivity of the nanotube. This approach to ethylene sensing also offers sub-ppm detection limits as well as response times on the order of seconds [125]. Advanced structures such as graphene oxidemodified iron oxides have pushed detection limits down to $10 \mathrm{ppb}$ while still retaining response times on the order of seconds [121]. These fast response times along with the simplicity of many chemiresistors continue to make them attractive for small and low-cost ethylene sensors.

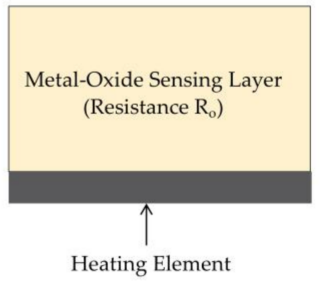

(a)

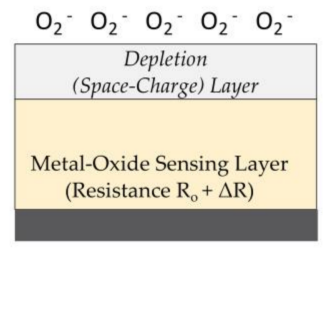

(b)

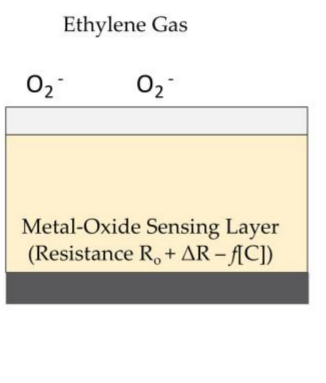

Figure 6. Metal-Oxide Gas Sensors. (a) In the absence of oxygen and reducing gases, the metal oxide has a baseline resistance on the order of kOhms. (b) Ambient oxygen on the surface of the sensing layer extracts oxygen from the underlying metal oxide, increasing resistance and creating a depletion (insulating) layer on the surface of the sensor. (c) A reducing gas such as ethylene binds with the oxygen on the surface, resulting in a re-injection of electrons into the sensing layer and a decrease in resistance that is a function of the ambient ethylene concentration. The heating element keeps the metal oxide sensing layer at an elevated temperature that maximizes the sensitivity of the sensor to desired gases.

Other materials have also demonstrated some potential for chemiresistive-based ethylene gas sensing. The perovskite $\mathrm{LaFeO}_{3}$ responds to ethylene at $150{ }^{\circ} \mathrm{C}$ but interference from acetylene gas and detection limits in the hundreds of ppm [126] limit its usefulness in farm-to-table operations. Still other structures and materials offer improvements in selectivity that are critical to the commercial use of these sensors in farm-to-table and other farming operations. The porous structure of metal organic frameworks (MOFs) offer ample opportunity to make size and chemical selective gateways for a variety of gas sensing materials. MOFs based on tetrahedrally-coordinated transition metal ions such as iron, copper, and zinc and connected by imidazolate linkers (e.g., ZIF-8) are especially attractive for low-cost ethylene sensors as they have demonstrated excellent ethylene adsorption properties [127].

The sensitivity of metal oxides to reducing gases such as ethylene can also be exploited using capacitance as the electrical output parameter. Tin oxide nanoparticles sandwiched between two copper electrodes have been demonstrated as effective chemicapacitors for detecting ethylene down to ppm ranges [128]. Selectivity to ethylene over other reducing gases can be enhanced by adding palladium or platinum between the electrodes and the metal oxide, but at the expense of faster degradation and shorter sensor 
lifetime [128]. Measuring capacitance rather than resistance offers similar short response times to resistance-based sensors while enabling ultra-low-power operation made possible by reading a signal from an insulator (via a capacitor) as opposed to a conductor (as is the case with a chemiresistor).

\section{Opportunities for Chemical Sensors in Farm-to-Table Operations}

While those who purchase and consume their food within farm-to-table operations often desire to support the local economy, sustain small- to medium-size family farms, and reduce the carbon footprint of what they eat, these are often not the primary goals of choosing farm-to-table over conventional corporate agriculture. Rather, the vast majority of those who access their food supply through farm-to-table pathways, whether home cook, restaurants, or entire chains of restaurants, are focused on the improvements in quality and freshness that farm-to-table provides. In many ways, the defining characteristics of farmto-table operations naturally improve quality. For instance, sourcing locally and directly from the farm reduces the time between harvest and consumption, thereby improving the nutritional value of both fruits and vegetables. Vastly reduced transport, distribution, and storage times also enable picking produce at near-optimal ripening rather than picking immature crops and artificially enhancing ripening (or delaying ripening) along the long road to the consumer. More optimal harvesting times, in turn, improve the balance between sweetness and acidity that ultimately determines the flavor of fruit at the point of consumption. If the only objective of farm-to-table were to deliver the same flavor of fruits and vegetables that corporate agricultural operations offer, additional sensing technology would be largely unneeded. However, as expectations for better flavor, better texture, and better overall fruit quality continue to rise, and particularly so for farm-to-table operations, integrating sensors along the pathway from pre-harvest to consumption becomes more and more essential to keeping up with consumer expectations.

While there is far more to flavor, taste, and overall perceptions of fruit quality than sweetness (measured as sugar content), acidity (measured as $\mathrm{pH}$ ), and ethylene (indicative of ripening stage), these three parameters provide a foundational chemical baseline for establishing and tracking fruit quality. When it comes to measuring sweetness in terms of total sugar content, most sensing technologies offer resolutions on the order of onetenth or one-quarter of one degree Brix (Table 4) which is more than sufficient to monitor changes in the sugar content of fruit from poor to excellent according to conventional ${ }^{\circ}$ Brix charts (Table 1). Optical methods (e.g., near-infrared spectroscopy) offer the added advantage of non-contact and non-destructive measurements at prediction errors of less than a single degree Brix (Table 5). Portable NIR spectrometers are available but their costs still run between $\$ 300$ and \$5000 USD [70]. This is substantially more than low-cost refractometers and hydrometers which offer similar resolution and accuracy in estimating total soluble solids content and total sugar content. A compromise between non-destructive but expensive and destructive but inexpensive approaches to measuring fruit sweetness may lie in the sampling approach. Advances in microsampling and microextraction of the internal solids of fruits have the potential to exploit the low-cost and low-power operation of refractometers and hydrometers while not visibly damaging the fruit, compromising its ripening behavior, or accelerating its degradation. While using RI or specific gravity as a measure of sweetness remains prone to errors from non-sucrose sugars and from non-sugar soluble solids, differentiating among these different forms of soluble solids is likely not necessary for estimating flavor and monitoring changes in sugar over time as fruit travels from harvest to consumption.

Estimates of flavor based on total sugar content alone can be highly inaccurate because acidity plays also plays an important role in perceived sweetness and overall flavor. Although titratable acidity offers a more accurate representation of total hydrogen ions and acid content in fruits, measuring it requires crushing and filtering the fruit as well as adding a known base to the resulting juice until a certain $\mathrm{pH}$ is reached. This method is inherently destructive and as a result, $\mathrm{pH}$ (i.e., free hydrogen ions in solution) is frequently 
used as a proxy for titratable acidity in evaluating fruit and fruit juice. Unlike sensors which determine sugar content to varying degrees across a wide range of price points, there is a large gap between $\mathrm{pH}$ sensors of coarse resolution (on the order of 1 or $0.1 \mathrm{pH}$ units) and higher performance $\mathrm{pH}$ meters which rely on electrochemical means to determine $\mathrm{pH}$. Like sugar sensors, however, $\mathrm{pH}$ sensors require converting intact fruit to mash which is inherently destructive to the fruit. The lowest cost alternatives to $\mathrm{pH}$ sensing involving strips that use multiple litmus indicators are vulnerable to human errors in judging the color of the strip, especially when stained by the fruit itself. Low-cost $\mathrm{pH}$ sensors (less than $\$ 40$ ) based on electrochemical sensing techniques are commercially available (Table 6) but calibration packages for these sensors can double the cost and a significant volume of liquid sample is still necessary. Viable, non-destructive techniques for $\mathrm{pH}$ sensing in farm-to-table operations may, like sugar content, involve using microextraction techniques to sample a small, low-impact volume of juice from the fruit. These low volume samples might then be analyzed using a custom calibrated litmus-indicator under controlled lighting conditions that offers resolution and accuracy on the order of tenths of $\mathrm{pH}$ units. Equally as viable are miniaturized electrochemical $\mathrm{pH}$ sensors which function with sufficiently small sample sizes to avoid significant degradation of the fruit being tested.

While sweetness and acidity contribute directly to perceptions of flavor and freshness, ethylene production among climacteric fruits and absorption by all fruits (and vegetables) plays a critical role in predicting flavor and freshness at the point of consumption. Too little ethylene in a climacteric fruit indicates a fruit not yet ready to be picked. Too much ethylene introduced on the route to the consumer poses a threat to all fruits in the vicinity of the excessive ethylene producer. Rates of change in ambient ethylene also provide valuable information about how much time a batch of fruit has before it becomes unsuitable for consumption. Unfortunately, most ethylene sensing technologies that are accurate and resistant to interference from other ambient gases are expensive and the performance of lower-cost alternatives is affected by ambient fruit metabolites such as ethanol. Nevertheless, chemiresistors and other low-cost ethylene sensors have the potential to be used for tracking aggregate changes in ambient ethylene gas as fruits travel to the consumer, thereby providing a low-resolution alarm that indicates conditions which could compromise entire batches of produce.

\section{Conclusions}

The benefits of farm-to-table farming to local economies, to small farms, to the health of the consumer, and to reductions in greenhouse gas emissions are many. In order to remain viable and to justify the additional cost and effort involved in navigating these farm-to-table operations, diversification of what farms offer must be balanced with consistent quality and freshness. Monitoring the chemistry of farm-to-table products as they travel from the point of harvest to the point of consumption is a small but important part of ensuring that the best flavor and optimal freshness is what the consumer ultimately experiences from these products. For fruit, flavor is a function of both sweetness and acidity-sugar content and $\mathrm{pH}$ (or titratable acidity). Freshness at the point of consumption can be estimated from ripeness at harvest, temperature, humidity, and other ambient conditions during storage and transport, and by emissions of and exposure to ethylene gas. In farm-to-table operations, transit and storage times are typically much shorter than in larger, corporatized agricultural operations. Thus, fruit can be picked closer to peak ripening and are more likely to arrive at the point of consumption with optimal flavor.

For non-climacteric fruit, sensing ethylene while the fruit is still on the vine (or tree) is not nearly as important as it is for climacteric fruit. For the latter, peak ethylene emissions and peak ripening go hand in hand. Handheld ethylene sensing instruments that can accurately track small changes in day-to-day ethylene emissions from climacteric fruit would allow harvesting decisions to be made with much greater precision than is presently possible. The most likely candidates for these handheld instruments are miniaturized gas chromatographs coupled with pre-concentrators that are immune to or 
that compensate for humidity in the ambient environment or coupled with detectors at the back-end that offer low enough detection limits that preconcentration is not needed. These instruments are likely to remain expensive but shared use among multiple farms in the same community can improve access to this important technology. Once fruit are harvested, monitoring ethylene exposure becomes important for both climacteric and nonclimacteric fruit. However, performance requirements for monitoring ethylene exposures and emissions are more relaxed. Instruments with high resolution and a continuous measurement range can likely be replaced with sensors that trigger only when ambient ethylene reaches levels that are known to trigger impending and premature degradation in certain types of fruit (or vegetables). In these scenarios, less accurate, more drift-prone, but dramatically less expensive sensors, such as metal oxide-based chemiresistors may deliver adequate performance over short transit and storage intervals to maximize yield and maintain freshness.

As for sugar and $\mathrm{pH}$, both are important for all types of fruit, whether climacteric or non-climacteric. Fortunately, low-cost options for sensing sugar content have been available for many decades and adjusting these options to farm-to-table operations is likely to be more about sampling than about sensing. Sugar must be measured in liquid samples and sensors or instruments that require low volume samples and sampling techniques that can non-destructively extract these liquid samples from intact fruit would open up a level of insight into the flavor of individual fruit that is out of reach with current technology. Similarly, $\mathrm{pH}$ must also be measured in liquid samples and having the capacity to monitor $\mathrm{pH}$ of fruit as it ripens, is harvested, and travels to its final destination without sacrificing individual fruit will be invaluable to tracking flavor and freshness. Unlike instruments and sensors that detect ${ }^{\circ}$ Brix (sugar content), however, $\mathrm{pH}$ sensing instruments remain relatively expensive and costs must be reduced to improve accessibility and value to farmto-table operations. Electrochemical $\mathrm{pH}$ sensors remain the most viable for $\mathrm{pH}$ sensing of fruit over the short term. Among these sensors, the need for a stable reference electrode is a major obstacle and investment in alternative paradigms that tolerate some instability in the electrochemical reference point may open the door to lower cost and possibly even single-use products for measuring $\mathrm{pH}$.

In summary, some problems associated with detecting $\mathrm{pH}$, sugar content, and ethylene in farm-to-table applications are constrained by what available sensing technologies can do. As a result, these problems are likely to be resolved (or alternatively, their limits of operation ultimately identified) as part of continued research on sensing materials and sensor designs in the broader research community. Other problems, however, require more attention to the constraints and unique needs of farm-to-table operations. These problems will benefit from engineering miniaturized versions of existing sensor technologies and integrating sampling techniques, sensors, interface circuits, and signal processing into user-friendly, application-sensitive instruments that are economically accessible to multiple stakeholders in farm-to-table operations. In short, there are ample opportunities for advances in sensors research and instrument engineering to better serve and support the farm-to-table community.

Funding: This research received no external funding.

Institutional Review Board Statement: This article did not involve human subjects.

Informed Consent Statement: Not applicable.

Data Availability Statement: No original data generated by the author is contained in this article.

Conflicts of Interest: The author declares no conflict of interest. 


\section{References}

1. Pirog, R.; Van Pelt, T.; Enshayan, K.; Cook, E. Food, Fuel and Freeways: An Iowa Perspective on How Far Food Travels, Fuel Usage, and Greenhouse Gas Emissions. Iowa State Univ. Leopold Cent. Publ. Pap. 2001.

2. Weber, C.L.; Matthews, H.S. Food-Miles and the Relative Climate Impacts of Food Choices in the United States. Environ. Sci Technol. 2008, 42, 3508-3513. [CrossRef] [PubMed]

3. Ritchie, H. You Want to Reduce the Carbon Footprint of Your Food? Focus on What You Eat, Not Whether Your Food Is Local. Available online: https: / / ourworldindata.org/food-choice-vs-eating-local (accessed on 30 January 2021).

4. Barrett, D. Maximizing the Nutritional Value of Fruits and Vegetables. Food Technol. 2007, 61, 40-44.

5. Kramer, A. Effect of Storage on Nutritive Value of Food. J. Food Qual. 1977, 1, 23-55. [CrossRef]

6. Howard, L.A.; Wong, A.D.; Perry, A.K.; Klein, B.P. $\beta$-Carotene and Ascorbic Acid Retention in Fresh and Processed Vegetables. J. Food Sci. 1999, 64, 929-936. [CrossRef]

7. Semuels, A. "They're Trying to Wipe Us Off the Map." Why Independent Farming in America Is Close to Extinction. Available online: https: / / time.com/5736789/small-american-farmers-debt-crisis-extinction/ (accessed on 31 January 2021).

8. Sowder, A. Is the Farm-to-Table Movement Good For Local Farmers and Food Businesses? Westchest. Mag. 2018.

9. Wilson, D. Tomatoes in the Diet. In Sensing the Perfect Tomato: An Internet of Sensing Approach; CRC Press: Boca Raton, FL, USA, 2019; pp. 13-26.

10. Corbett, L.C. Color as an indication of the picking maturity of fruits and vegetables. In Yearbook of the Department of Agriculture; US Department of Agriculture: Washington DC, USA, 1917; pp. 99-106.

11. Maturity Indicators (University of Maine Cooperative Extension). Available online: https://extension.umaine.edu/fruit/harvestand-storage-of-tree-fruits / maturity-indicators / (accessed on 29 January 2021).

12. Bertin, N.; Génard, M. Tomato Quality as Influenced by Preharvest Factors. Sci. Hortic. 2018, 233, 264-276. [CrossRef]

13. Harrill, R. Using a Refractometer to Test the Quality of Fruits and Vegetables. P Publ. Éd Consulté July 1998, $20,2010$.

14. Islam, M.K.; Khan, M.Z.H.; Sarkar, M.A.R.; Absar, N.; Sarkar, S.K. Changes in Acidity, TSS, and Sugar Content at Different Storage Periods of the Postharvest Mango (Mangifera Indica L.) Influenced by Bavistin DF. Int. J. Food Sci. 2013, 2013, e939385. [CrossRef] [PubMed]

15. Alizadeh, K.; Fatholahi, S.; Teixeira da Silva, J.A. Variation in the Fruit Characteristics of Local Pear (Pyrus Spp.) in the Northwest of Iran. Genet. Resour. Crop Evol. 2015, 62, 635-641. [CrossRef]

16. Canadian Sugar Institute. Sources of Sugar. Available online: https://sugar.ca/sugar-basics/sources-of-sugar (accessed on 29 January 2021).

17. U.S. Production of Tomatoes for Processing 2018. Available online: https://www.statista.com/statistics/193237/us-tomatoproduction-for-processing-since-2000/ (accessed on 30 January 2021).

18. Anthon, G.E.; LeStrange, M.; Barrett, D.M. Changes in PH, Acids, Sugars and Other Quality Parameters during Extended Vine Holding of Ripe Processing Tomatoes. J. Sci. Food Agric. 2011, 91, 1175-1181. [CrossRef]

19. Monti, L.M. The Breeding of Tomatoes for Peeling. In Symposium on Production of Tomatoes for Processing 100; ISHS: Leuven, Belgium, 1979; pp. 341-354.

20. US FDA/CFSAN-Approximate PH of Foods and Food Products. Available online: https://www.webpal.org/SAFE/ aaarecovery/2_food_storage/Processing/lacf-phs.htm (accessed on 29 January 2021).

21. Sweeney, J.P.; Chapman, V.J.; Hepner, P.A. Sugar, Acid, and Flavor in Fresh Fruits. J. Am. Diet. Assoc. 1970, 57, $432-435$.

22. Batista-Silva, W.; Nascimento, V.L.; Medeiros, D.B.; Nunes-Nesi, A.; Ribeiro, D.M.; Zsögön, A.; Araújo, W.L. Modifications in Organic Acid Profiles During Fruit Development and Ripening: Correlation or Causation? Front. Plant Sci. 2018, 9, 1689. [CrossRef]

23. Yamaki, S. Isolation of Vacuoles from Immature Apple Fruit Flesh and Compartmentation of Sugars, Organic Acids, Phenolic Compounds and Amino Acids. Plant Cell Physiol. 1984, 25, 151-166. [CrossRef]

24. Yamaki, Y.T. Organic Acids in the Juice of Citrus Fruits. J. Jpn. Soc. Hortic. Sci. 1989, 58, 587-594. [CrossRef]

25. Li, X.; Zhang, J.-Y.; Gao, W.-Y.; Wang, Y.; Wang, H.-Y.; Cao, J.-G.; Huang, L.-Q. Chemical Composition and Anti-Inflammatory and Antioxidant Activities of Eight Pear Cultivars. J. Agric. Food Chem. 2012, 60, 8738-8744. [CrossRef] [PubMed]

26. Bugaud, C.; Deverge, E.; Daribo, M.-O.; Ribeyre, F.; Fils-Lycaon, B.; Mbéguié-A-Mbéguié, D. Sensory Characterisation Enabled the First Classification of Dessert Bananas. J. Sci. Food Agric. 2011, 91, 992-1000. [CrossRef]

27. Etienne, C.; Rothan, C.; Moing, A.; Plomion, C.; Bodénès, C.; Svanella-Dumas, L.; Cosson, P.; Pronier, V.; Monet, R.; Dirlewanger, E. Candidate Genes and QTLs for Sugar and Organic Acid Content in Peach [Prunus Persica (L.) Batsch]. Theor. Appl. Genet. 2002, 105, 145-159. [CrossRef]

28. Paul, V.; Pandey, R.; Srivastava, G.C. The Fading Distinctions between Classical Patterns of Ripening in Climacteric and Non-Climacteric Fruit and the Ubiquity of Ethylene-An Overview. J. Food Sci. Technol. 2012, 49, 1-21. [CrossRef]

29. Alos, E.; Rodrigo, M.J.; Zacarias, L. Ripening and Senescence. In Postharvest Physiology and Biochemistry of Fruits and Vegetables; Elsevier: Amsterdam, The Netherlands, 2018; pp. 131-156.

30. Kader, A.A. Quality parameters of fresh-cut fruit and vegetable products. In Fresh cut Fruits and Vegetables: Science, Technology, and Market; CRC Press: Boca Raton, FL, USA, 2001; pp. 23-32.

31. Kader, A. Postharvest Biology and Technology: An Overview. In Postharvest Technology of Horticultural Crops; University of California Agriculture and Natural Resources: Davis, CA, USA, 2002. 
32. Janssen, S.; Schmitt, K.; Blanke, M.; Bauersfeld, M.L.; Wöllenstein, J.; Lang, W. Ethylene Detection in Fruit Supply Chains. Philos. Transact. A Math. Phys. Eng. Sci. 2014, 372. [CrossRef]

33. Naeve, L. Store Fresh Garden Produce Properly. Available online: https://www.extension.iastate.edu/smallfarms/store-freshgarden-produce-properly (accessed on 30 January 2021).

34. Okoye, C.O.B.; Ibeto, C.N. Analysis of Different Brands of Fruit Juice with Emphasis on Their Sugar and Trace Metal Content. Bio-Research 2009, 7. [CrossRef]

35. Mettler-Toledo International Brix Sugar Determination. Available online: https://beta-static.fishersci.com/content/dam/ fishersci/en_US/documents / programs / scientific/technical-documents/technical-bulletins/mettler-toledo-brix-sugardetermination-techinical-bulletin.pdf (accessed on 30 January 2021).

36. Northern Brewer Hydrometers \& Refractometers. Available online: https://www.northernbrewer.com/collections/hydrometersrefractometers (accessed on 26 January 2021).

37. Fisher Scientific Fisherbrand ASTM Specific Gravity $260 \mathrm{~mL}$ Hydrometers for Liquids Heavier than Water. Available online: https:/ / www.fishersci.com/shop/products/fisherbrand-astm-specific-gravity-hydrometers-liquids-heavier-than-water260ml-liquid-volume-32/p-4279040 (accessed on 26 January 2021).

38. Density Meters. Available online: https://www.anton-paar.com/us-en/products/group/density-meter/ (accessed on 26 January 2021).

39. Yunus, W.M.; Rahman, A.B. Refractive Index of Solutions at High Concentrations. Appl. Opt. 1988, 27, 3341-3343. [CrossRef]

40. Pratt, S. The Importance of Temperature Control with Abbe Refractometers. Available online: https://assets.fishersci.com/TFSAssets/LED/Application-Notes/D01627 \{\}.pdf (accessed on 25 February 2021).

41. Piliarik, M.; Homola, J. Surface Plasmon Resonance (SPR) Sensors: Approaching Their Limits? Opt. Express 2009, 17, 16505-16517. [CrossRef]

42. Hanumegowda, N.M.; Stica, C.J.; Patel, B.C.; White, I.; Fan, X. Refractometric Sensors Based on Microsphere Resonators. Appl. Phys. Lett. 2005, 87, 201107. [CrossRef]

43. Kang, Y.Q.; François, A.; Riesen, N.; Monro, T.M. Mode-Splitting for Refractive Index Sensing in Fluorescent Whispering Gallery Mode Microspheres with Broken Symmetry. Sensors 2018, 18, 2987. [CrossRef]

44. Chow, E.; Grot, A.; Mirkarimi, L.W.; Sigalas, M.; Girolami, G. Ultracompact Biochemical Sensor Built with Two-Dimensional Photonic Crystal Microcavity. Opt. Lett. 2004, 29, 1093-1095. [CrossRef] [PubMed]

45. Kassa-Baghdouche, L. High-Sensitivity Spectroscopic Gas Sensor Using Optimized H1 Photonic Crystal Microcavities. JOSA B 2020, 37, A277-A284. [CrossRef]

46. Hu, H.; Du, C.; Wang, Q.; Wang, X.; Zhao, Y. High Sensitivity Internal Refractive Index Sensor Based on a Photonic Crystal Fiber Long Period Grating. Instrum. Sci. Technol. 2017, 45, 181-189. [CrossRef]

47. Angkawisittpan, N.; Manasri, T. Determination of Sugar Content in Sugar Solutions Using Interdigital Capacitor Sensor. Meas. Sci. Rev. 2012, 12, 8-13. [CrossRef]

48. Bhosale, A.A. Detection of Sugar Content in Citrus Fruits by Capacitance Method. Procedia Eng. 2017, 181, 466-471. [CrossRef]

49. Contreras, N.I.; Fairley, P.; McClements, D.J.; Povey, M.J.W. Analysis of the Sugar Content of Fruit Juices and Drinks Using Ultrasonic Velocity Measurements. Int. J. Food Sci. Technol. 1992, 27, 515-529. [CrossRef]

50. Mizrach, A. Ultrasonic Technology for Quality Evaluation of Fresh Fruit and Vegetables in Pre- and Postharvest Processes Postharvest Biol. Technol. 2008, 48, 315-330. [CrossRef]

51. Northern Brewer Herculometer ${ }^{\circledR}$-Triple Scale Hydrometer. Available online: https://www.northernbrewer.com/products / herculometer-triple-scale-hydrometer (accessed on 27 January 2021).

52. Cole-Parmer 0/35 Degree Brix Sugar Scale Shatterproof Plastic Hydrometer. Available online: https://www.coleparmer.com/i/ cole-parmer-0-35-degree-brix-sugar-scale-shatterproof-plastic-hydrometer/0829836 (accessed on 27 January 2021).

53. Mettler Toledo Handheld Density Meter. Available online: https://www.fishersci.com/shop/products/densito-handhelddensity-meter / 01915180 (accessed on 27 January 2021).

54. Fisherbrand Handheld Analog Brix/Sucrose Refractometer. Available online: https://www.fishersci.com/shop/products/ handheld-analog-brix-sucrose-refractometer-10/p-7113344 (accessed on 27 January 2021).

55. Fisherbrand Handheld Digital Brix/RI Refractometer. Available online: https://www.fishersci.com/shop/products/fisherbrandhandheld-digital-brix-ri-refractometer-7/p-8433003 (accessed on 27 January 2021).

56. Fisherbrand Analog Abbe Benchtop RI Refractometer. Available online: https:/ /www.fishersci.com/shop/products/benchabbe-refract-brix-ri/12561359 (accessed on 27 January 2021).

57. Golic, M.; Walsh, K.; Lawson, P. Short-Wavelength Near-Infrared Spectra of Sucrose, Glucose, and Fructose with Respect to Sugar Concentration and Temperature. Appl. Spectrosc. 2003, 57, 139-145. [CrossRef] [PubMed]

58. Yan, H.; Han, B.; Siesler, H. Handheld Near-Infrared Spectrometers: Reality and Empty Promises. Spectroscopy 2020, $35,15-18$.

59. Pasquini, C. Near Infrared Spectroscopy: Fundamentals, Practical Aspects and Analytical Applications. J. Braz. Chem. Soc. 2003, 14, 198-219. [CrossRef]

60. Pissard, A.; Pierna, J.A.F.; Baeten, V.; Sinnaeve, G.; Lognay, G.; Mouteau, A.; Dupont, P.; Rondia, A.; Lateur, M. Non-Destructive Measurement of Vitamin C, Total Polyphenol and Sugar Content in Apples Using near-Infrared Spectroscopy. J. Sci. Food Agric. 2013, 93, 238-244. [CrossRef] [PubMed] 
61. Lu, R.; Guyer, D.E.; Beaudry, R.M. Determination of Firmness and Sugar Content of Apples Using Near-Infrared Reflectance. J. Texture Stud. 2000, 31, 615-630. [CrossRef]

62. Xudong, S.; Hailiang, Z.; Yande, L. Nondestructive Assessment of Quality of Nanfeng Mandarin Fruit by a Portable near Infrared Spectroscopy. Int. J. Agric. Biol. Eng. 2009, 2, 65-71.

63. McGlone, V.A.; Fraser, D.G.; Jordan, R.B.; Künnemeyer, R. Internal Quality Assessment of Mandarin Fruit by Vis/NIR Spectroscopy. J. Infrared Spectrosc. 2003, 11, 323-332. [CrossRef]

64. Liu, Y.; Sun, X.; Ouyang, A. Nondestructive Measurement of Soluble Solid Content of Navel Orange Fruit by Visible-NIR Spectrometric Technique with PLSR and PCA-BPNN. LWT-Food Sci. Technol. 2010, 43, 602-607. [CrossRef]

65. Miller, W.M.; Zude-Sasse, M. NIR-based sensing to measure soluble solids content of Florida citrus. Appl. Eng. Agric. 2004, 20, 321-327. [CrossRef]

66. Guo, Y.; Ni, Y.; Kokot, S. Evaluation of Chemical Components and Properties of the Jujube Fruit Using near Infrared Spectroscopy and Chemometrics. Spectrochim. Acta. A. Mol. Biomol. Spectrosc. 2016, 153, 79-86. [CrossRef]

67. Maniwara, P.; Nakano, K.; Boonyakiat, D.; Ohashi, S.; Hiroi, M.; Tohyama, T. The Use of Visible and near Infrared Spectroscopy for Evaluating Passion Fruit Postharvest Quality. J. Food Eng. 2014, 143, 33-43. [CrossRef]

68. Wang, J.; Wang, J.; Chen, Z.; Han, D. Development of Multi-Cultivar Models for Predicting the Soluble Solid Content and Firmness of European Pear (Pyrus Communis L.) Using Portable Vis-NIR Spectroscopy. Postharvest Biol. Technol. 2017, 129, 143-151. [CrossRef]

69. Guo, Z.; Huang, W.; Chen, L.; Wang, X.; Peng, Y. Nondestructive Evaluation of Soluble Solid Content in Strawberry by near Infrared Spectroscopy. In Proceedings of the PIAGENG 2013: Image Processing and Photonics for Agricultural Engineering; International Society for Optics and Photonics, Sanya, China, 4 March 2013; Volume 8761, p. 87610O.

70. Marques, E.J.N.; de Freitas, S.T. Performance of New Low-Cost Handheld NIR Spectrometers for Nondestructive Analysis of Umbu (Spondias Tuberosa Arruda) Quality. Food Chem. 2020, 323, 126820. [CrossRef]

71. Cen, H.; He, Y.; Huang, M. Measurement of Soluble Solids Contents and PH in Orange Juice Using Chemometrics and Vis-NIRS. J. Agric. Food Chem. 2006, 54, 7437-7443. [CrossRef] [PubMed]

72. Pennsylvania State University Acid Base Indicators. Available online: http://chemistry.bd.psu.edu/jircitano/abindic.html (accessed on 28 October 2018).

73. Janata, J. Electrochemical Microsensors. Proc. IEEE 2003, 91, 864-869. [CrossRef]

74. Chudy, M.; Wroblewski, W.; Brzózka, Z. Towards REFET. Sens. Actuators B Chem. 1999, 57, 47-50. [CrossRef]

75. Qin, Y.; Kwon, H.-J.; Howlader, M.M.R.; Deen, M.J. Microfabricated Electrochemical pH and Free Chlorine Sensors for Water Quality Monitoring: Recent Advances and Research Challenges. RSC Adv. 2015, 5, 69086-69109. [CrossRef]

76. Spijkman, M.; Smits, E.C.P.; Cillessen, J.F.M.; Biscarini, F.; Blom, P.W.M.; de Leeuw, D.M. Beyond the Nernst-Limit with Dual-Gate ZnO Ion-Sensitive Field-Effect Transistors. Appl. Phys. Lett. 2011, 98, 043502. [CrossRef]

77. MicroSens Ion Sensitive Field-Effect Transistor-ISFET. Available online: http://microsens.ch/products/pdf/MSFET_Datasheet. pdf (accessed on 25 February 2021).

78. Hanna Instruments Edge Digital PH Meter-HI2002-01. Available online: https://www.hannainst.com/edge-dedicated-ph-orpmeter.html (accessed on 31 January 2021).

79. Waterproof Pocket PH Tester with 0.1 Resolution-PHep®-HI98107. Available online: https://www.hannainst.com/hi98107-phepph-tester.html (accessed on 31 January 2021).

80. Sinha, S.; Mukhiya, R.; Sharma, R.; Khanna, P.K.; Khanna, V.K. Fabrication, Characterization and Electrochemical Simulation of AlN-Gate ISFET PH Sensor. J. Mater. Sci. Mater. Electron. 2019, 30, 7163-7174. [CrossRef]

81. MicroSens MSFET 3332 PH-ISFET Sensor Module. Available online: http:/ / microsens.ch/products/MSFET.htm (accessed on 31 January 2021).

82. Shawkat, M.S.A.; McFarlane, N. A Single-Chip ISFET Based PH Sensor. In Proceedings of the IEEE Sensors, Orlando, FL, USA, 30 October-3 November 2016; pp. 1-3.

83. Sharma, P.; Gupta, S.; Singh, R.; Ray, K.; Kothari, S.L.; Sinha, S.; Sharma, R.; Mukhiya, R.; Awasthi, K.; Kumar, M. Hydrogen Ion Sensing Characteristics of $\mathrm{Na}_{3} \mathrm{BiO}_{4}-\mathrm{Bi}_{2} \mathrm{O}_{3}$ Mixed Oxide Nanostructures Based EGFET pH Sensor. Int. J. Hydrogen Energy 2020, 45, 18743-18751. [CrossRef]

84. Sabah, F.A.; Ahmed, N.M.; Hassan, Z.; Almessiere, M.A. Influence of CuS Membrane Annealing Time on the Sensitivity of EGFET PH Sensor. Mater. Sci. Semicond. Process. 2017, 71, 217-225. [CrossRef]

85. Jeon, J.-H.; Cho, W.-J. Ultrasensitive Coplanar Dual-Gate ISFETs for Point-of-Care Biomedical Applications. ACS Omega 2020, 5, 12809-12815. [CrossRef]

86. Arshak, A.; Gill, E.; Arshak, K.; Korostynska, O.; Cunniffe, C. Drop-Coated Polyaniline Composite Conductimetric PH Sensors. In Proceedings of the 30th IEEE International Spring. Seminar on Electronics Technology, Cluj-Napoca, Romania, 9-13 May 2007; pp. 213-218.

87. Gill, E.; Arshak, A.; Arshak, K.; Korostynska, O. Conductimetric PH Sensor Based on Novel Conducting Polymer Composite Thick Films. In Proceedings of the 2008 31st International Spring Seminar on Electronics Technology, Budapest, Hungary, 7-11 May 2008; pp. 478-483.

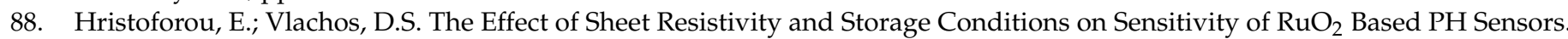
Available online: https:/ / www.scientific.net/KEM.605.457 (accessed on 12 November 2018). 
89. Gill, E.; Arshak, K.; Arshak, A.; Korostynska, O. Mixed Metal Oxide Films as PH Sensing Materials. Microsyst. Technol. 2008, 14, 499-507. [CrossRef]

90. Richter, A.; Paschew, G.; Klatt, S.; Lienig, J.; Arndt, K.-F.; Adler, H.-J.P. Review on Hydrogel-Based PH Sensors and Microsensors. Sensors 2008, 8, 561-581. [CrossRef] [PubMed]

91. Boisen, A.; Thundat, T. Design \& Fabrication of Cantilever Array Biosensors. Mater. Today 2009, 12, 32-38. [CrossRef]

92. Roy, S.K.; Sauer, V.T.K.; Westwood-Bachman, J.N.; Venkatasubramanian, A.; Hiebert, W.K. Improving Mechanical Sensor Performance through Larger Damping. Science 2018, 360, eaar5220. [CrossRef]

93. Wencel, D.; Abel, T.; McDonagh, C. Optical Chemical PH Sensors. Anal. Chem. 2014, 86, 15-29. [CrossRef]

94. Cristescu, S.M.; Mandon, J.; Arslanov, D.; De Pessemier, J.; Hermans, C.; Harren, F.J.M. Current Methods for Detecting Ethylene in Plants. Ann. Bot. 2013, 111, 347-360. [CrossRef]

95. Saltveit Jr, M.E. Internal Carbon Dioxide and Ethylene Levels in Ripening Tomato Fruit Attached to or Detached from the Plant. Physiol. Plant. 1993, 89, 204-210. [CrossRef]

96. Levin, A.; Meyer, C.F. The Infrared Absorption Spectra of Acetylene, Ethylene and Ethane. JOSA 1928, 16, 137-164. [CrossRef]

97. Harren, F.J.M.; Bijnen, F.G.C.; Reuss, J.; Voesenek, L.A.C.J.; Blom, C.W.P.M. Sensitive Intracavity Photoacoustic Measurements with a $\mathrm{CO}_{2}$ Waveguide Laser. Appl. Phys. B 1990, 50, 137-144. [CrossRef]

98. Altuzar, V.; Pacheco, M.; Tomás, S.A.; Arriaga, J.L.; Zelaya-Angel, O.; Sánchez-Sinencio, F. Analysis of Ethylene Concentration in the Mexico City Atmosphere by Photoacoustic Spectroscopy. Anal. Sci. 2002, 17icpp, s541-s543. [CrossRef]

99. Teodoro, C.G.; Schramm, D.U.; Sthel, M.S.; Lima, G.R.; Rocha, M.V.; Tavares, J.R.; Vargas, H. CO 2 Laser Photoacoustic Detection of Ethylene Emitted by Diesel Engines Used in Urban Public Transports. Infrared Phys. Technol. 2010, 53, 151-155. [CrossRef]

100. Scotoni, M.; Rossi, A.; Bassi, D.; Buffa, R.; Iannotta, S.; Boschetti, A. Simultaneous Detection of Ammonia, Methane and Ethylene at 1.63 Mm with Diode Laser Photoacoustic Spectroscopy. Appl. Phys. B 2006, 82, 495-500. [CrossRef]

101. Schilt, S.; Kosterev, A.A.; Tittel, F.K. Performance Evaluation of a near Infrared QEPAS Based Ethylene Sensor. Appl. Phys. B 2009, 95, 813-824. [CrossRef]

102. Gasera Gasera F10 Analyzer. Available online: https://d3pcsg2wjq9izr.cloudfront.net/files/49823/download/661215/0-1.pdf (accessed on 18 August 2020).

103. Kitson, F.G.; Larsen, B.S.; McEwen, C.N. Gas Chromatography and Mass Spectrometry; Elsevier: New York, NY, USA, 1996; ISBN 978-0-12-483385-2.

104. Alfeeli, B. Chemical Micro Preconcentrators Development for Micro Gas Chromatography Systems. Ph.D. Thesis, Virginia Tech, Blacksburg, VA, USA, 2010.

105. Sklorz, A.; Janßen, S.; Lang, W. Gas Chromatograph Based on Packed MGC-Columns and $\mu$-Preconcentrator Devices for Ethylene Detection in Fruit Logistic Applications. Procedia Eng. 2012, 47, 486-489. [CrossRef]

106. Sklorz, A.; Janßen, S.; Lang, W. Application of a Miniaturised Packed Gas Chromatography Column and a SnO 2 Gas Detector for Analysis of Low Molecular Weight Hydrocarbons with Focus on Ethylene Detection. Sens. Actuators B Chem. 2013, 180, 43-49. [CrossRef]

107. Lucklum, F.; Janssen, S.; Lang, W.; Vellekoop, M.J. Miniature 3D Gas Chromatography Columns with Integrated Fluidic Connectors Using High-Resolution Stereolithography Fabrication. Procedia Eng. 2015, 120, 703-706. [CrossRef]

108. Zaidi, N.A.; Tahir, M.W.; Vinayaka, P.P.; Lucklum, F.; Vellekoop, M.; Lang, W. Detection of Ethylene Using Gas Chromatographic System. Procedia Eng. 2016, 168, 380-383. [CrossRef]

109. Venkatasubramanian, A.; Sauer, V.T.K.; Roy, S.K.; Xia, M.; Wishart, D.S.; Hiebert, W.K. Nano-Optomechanical Systems for Gas Chromatography. Nano Lett. 2016, 16, 6975-6981. [CrossRef]

110. Morsy, N.; Sun, D.-W. Robust Linear and Non-Linear Models of NIR Spectroscopy for Detection and Quantification of Adulterants in Fresh and Frozen-Thawed Minced Beef. Meat Sci. 2013, 93, 292-302. [CrossRef] [PubMed]

111. Cozzolino, D. Recent Trends on the Use of Infrared Spectroscopy to Trace and Authenticate Natural and Agricultural Food Products. Appl. Spectrosc. Rev. 2012, 47, 518-530. [CrossRef]

112. Makio, T.; Hiroaki, I.; Tomohiro, T.; Hisaya, Y.; Kumiko, N.; Nobuaki, T. Classification of Pesticide Residues in the Agricultural Products Based on Diffuse Reflectance IR Spectroscopy. In Proceedings of the SICE Annual Conference 2007, Takamatsu, Japan, 17-20 September 2007; pp. 216-219.

113. Shenk, J.S.; Workman Jr, J.J.; Westerhaus, M.O. Application of NIR Spectroscopy to Agricultural Products. In Handbook of Near-Infrared Analysis; CRC Press: Boca Raton, FL, USA, 2007; pp. 347-386.

114. SmartGAS C2H4 Sensors. Available online: https://www.smartgas.eu/en/gases/c2h4-sensors/ (accessed on 19 August 2020).

115. Sklorz, A.; Schafer, A.; Lang, W. Merging Ethylene NDIR Gas Sensors with Preconcentrator-Devices for Sensitivity Enhancement. Sens. Actuators B Chem. 2012, 170, 21-27. [CrossRef]

116. Kathirvelan, J.; Vijayaraghavan, R. An Infrared Based Sensor System for the Detection of Ethylene for the Discrimination of Fruit Ripening. Infrared Phys. Technol. 2017, 85, 403-409. [CrossRef]

117. Toldra-Reig, F.; Serra, J.M. Development of Potentiometric Sensors for $\mathrm{C}_{2} \mathrm{H}_{4}$ Detection. Sensors 2018, 18, 2992. [CrossRef]

118. Zevenbergen, M.A.; Wouters, D.; Dam, V.-A.T.; Brongersma, S.H.; Crego-Calama, M. Electrochemical Sensing of Ethylene Employing a Thin Ionic-Liquid Layer. Anal. Chem. 2011, 83, 6300-6307. [CrossRef] [PubMed] 
119. Ma, L.; Wang, L.; Chen, R.; Chang, K.; Wang, S.; Hu, X.; Sun, X.; Lu, Z.; Sun, H.; Guo, Q.; et al. A Low Cost Compact Measurement System Constructed Using a Smart Electrochemical Sensor for the Real-Time Discrimination of Fruit Ripening. Sensors 2016, 16, 501. [CrossRef]

120. Leangtanom, P.; Wisitsoraat, A.; Jaruwongrungsee, K.; Chanlek, N.; Phanichphant, S.; Kruefu, V. Highly Sensitive and Selective Ethylene Gas Sensors Based on $\mathrm{CeOx}-\mathrm{SnO}_{2}$ Nanocomposites Prepared by a Co-Precipitation Method. Mater. Chem. Phys. 2020, 254, 123540. [CrossRef]

121. Li, B.; Li, M.; Meng, F.; Liu, J. Highly Sensitive Ethylene Sensors Using Pd Nanoparticles and RGO Modified Flower-like Hierarchical Porous $\alpha-\mathrm{Fe}_{2} \mathrm{O}_{3}$. Sens. Actuators B Chem. 2019, 290, 396-405. [CrossRef]

122. Zhao, Q.; Duan, Z.; Yuan, Z.; Li, X.; Si, W.; Liu, B.; Zhang, Y.; Jiang, Y.; Tai, H. High Performance Ethylene Sensor Based on Palladium-Loaded Tin Oxide: Application in Fruit Quality Detection. Chin. Chem. Lett. 2020, 31, 2045-2049. [CrossRef]

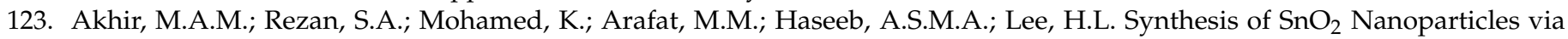
Hydrothermal Method and Their Gas Sensing Applications for Ethylene Detection. Mater. Today Proc. 2019, 17, 810-819. [CrossRef]

124. Esser, B.; Schnorr, J.M.; Swager, T.M. Selective Detection of Ethylene Gas Using Carbon Nanotube-Based Devices: Utility in Determination of Fruit Ripeness. Angew. Chem. Int. Ed. 2012, 51, 5752-5756. [CrossRef]

125. Trafton, A. New Sensor Could Help Prevent Food Waste. MIT News 2020.

126. Alharbi Abdulaziz, A.; Sackmann, A.; Weimar, U.; Bârsan, N. Acetylene- and Ethylene-Sensing Mechanism for LaFeO 3 -Based Gas Sensors: Operando Insights. J. Phys. Chem. C 2020, 124, 7317-7326. [CrossRef]

127. Falcaro, P.; Ricco, R.; Yazdi, A.; Imaz, I.; Furukawa, S.; Maspoch, D.; Ameloot, R.; Evans, J.D.; Doonan, C.J. Application of Metal and Metal Oxide Nanoparticles@MOFs. Coord. Chem. Rev. 2016, 307, 237-254. [CrossRef]

128. Agarwal, M.; Balachandran, M.D.; Shrestha, S.; Varahramyan, $\mathrm{K}$. $\mathrm{SnO}_{2}$ Nanoparticle-Based Passive Capacitive Sensor for Ethylene Detection. J. Nanomater. 2012, 2012, e145406. [CrossRef] 